\title{
Brazilian guidelines for the clinical management of paracoccidioidomycosis
}

\author{
Maria Aparecida Shikanai-Yasuda ${ }^{[1]}$, Rinaldo Pôncio Mendes ${ }^{[2]}$, Arnaldo Lopes Colombo ${ }^{[3]}$, \\ Flávio de Queiroz-Telles ${ }^{[4]}$, Adriana Satie Gonçalves Kono ${ }^{[5]}$, Anamaria M. M. Paniago ${ }^{[6]}$, \\ André Nathan ${ }^{[7]}$, Antonio Carlos Francisconi do Valle ${ }^{[8]}$, Eduardo Bagagli ${ }^{[9]}$, \\ Gil Benard ${ }^{[10]}$, Marcelo Simão Ferreira ${ }^{[11]}$, Marcus de Melo Teixeira ${ }^{[12]}$, \\ Mario León Silva-Vergara ${ }^{[13]}$, Ricardo Mendes Pereira ${ }^{[14]}$, Ricardo de Souza Cavalcante ${ }^{[2]}$, \\ Rosane Hahnn ${ }^{[15]}$, Rui Rafael Durlacher ${ }^{[16]}$, Zarifa Khoury[17], Zoilo Pires de Camargo ${ }^{[18],}$ \\ Maria Luiza Moretti[19], and Roberto Martinez ${ }^{[20]}$
}

\begin{abstract}
[1]. Departamento de Moléstias Infecciosas e Parasitárias, Faculdade de Medicina, Universidade de São Paulo, São Paulo, SP, Brasil.
[2]. Departamento de Doenças Tropicais e Diagnóstico por Imagem, Faculdade de Medicina Botucatu, Universidade Estadual Paulista, Botucatu, SP, Brasil. [3]. Departamento de Medicina, Escola Paulista de Medicina, Universidade Federal de São Paulo, São Paulo, SP, Brasil. [4]. Departamento de Saúde Comunitária, Universidade Federal do Paraná, Curitiba, PR, Brasil. [5]. Divisão de Moléstias Infecciosas, Hospital das Clínicas, Faculdade de Medicina, Universidade de São Paulo, São Paulo, SP, Brasil. [6]. Faculdade de Medicina, Universidade Federal de Mato Grosso do Sul, Campo Grande, MS, Brasil. [7]. Divisão de Pneumologia, Hospital das Clínicas, Faculdade de Medicina, Universidade de São Paulo, São Paulo, SP, Brasil.

[8]. Instituto de Pesquisa Clínica Evandro Chagas, Fundação Oswaldo Cruz, Rio de Janeiro, RJ, Brasil. [9]. Departamento de Microbiologia e Imunologia, Instituto de Biociências, Universidade Estadual Paulista, Botucatu, SP, Brasil. [10]. Departamento de Dermatologia, Faculdade de Medicina, Universidade de São Paulo, São Paulo, SP, Brasil. [11]. Serviço de Infectologia, Faculdade de Medicina, Universidade Federal de Uberlândia, Uberlândia, MG, Brasil. [12]. Translational Genomics Research Institute, Northern Arizona University, AZ, USA. [13]. Departamento de Clínica Médica, Faculdade de Medicina, Universidade Federal do Triângulo Mineiro, Uberaba, MG. Brasil. [14]. Departamento de Pediatria, Faculdade de Ciências Médicas, Universidade Estadual de Campinas, Campinas, SP, Brasil. [15]. Núcleo de Doenças Infecciosas e Tropicais, Faculdade de Ciências Médicas, Universidade Federal de Mato Grosso, Cuiabá, MT, Brasil. [16]. Centro de Medicina Tropical de Rondônia, Porto Velho, RO, Brasil. [17]. Instituto de Infectologia Emílio Ribas, Secretaria de Estado da Saúde de São Paulo, São Paulo, SP, Brasil. [18]. Departamento de Microbiologia e Imunologia, Universidade Federal de São Paulo, São Paulo, SP, Brasil.

[19]. Departamento de Clínica Médica, Faculdade Ciências Médicas, Universidade Estadual de Campinas, Campinas, SP, Brasil.

[20]. Departamento de Clínica Médica, Faculdade de Medicina de Ribeirão Preto, Universidade de São Paulo, Ribeirão Preto, SP, Brasil.
\end{abstract}

\begin{abstract}
Paracoccidioidomycosis is a systemic fungal disease occurring in Latin America that is associated with rural environments and agricultural activities. However, the incidence and prevalence of paracoccidiodomycosis is underestimated because of the lack of compulsory notification. If paracoccidiodomycosis is not diagnosed and treated early and adequately, the endemic fungal infection could result in serious sequelae. While the Paracoccidioides brasiliensis (P. brasiliensis) complex has been known to be the causal agent of paracoccidiodomycosis, a new species, Paracoccidioides lutzii (P. lutzii), has been reported in Rondônia, where the disease has reached epidemic levels, and in the Central West and Pará. Accurate diagnoses and availability of antigens that are reactive with the patients' sera remain significant challenges. Therefore, the present guidelines aims to update the first Brazilian consensus on paracoccidioidomycosis by providing evidence-based recommendations for bedside patient management. This consensus summarizes etiological, ecoepidemiological, molecular epidemiological, and immunopathological data, with emphasis on clinical, microbiological, and serological diagnosis and management of clinical forms and sequelae, as well as in patients with comorbidities and immunosuppression. The consensus also includes discussion of outpatient treatments, severe disease forms, disease prevalence among special populations and resource-poor settings, a brief review of prevention and control measures, current challenges and recommendations.
\end{abstract}

Keywords: Paracoccidioidomycosis. Guidelines. Clinical management. Diagnosis. Treatment follow-up.

Corresponding author: Profa. Maria Aparecida Shikanai-Yasuda.

email: masyasuda@yahoo.com.br

Received 01 June 2017

Accepted 30 June 2017 


\section{ETIOLOGY}

Paracoccidioidomycosis (PCM) is caused by thermodimorphic fungi that currently encompasses two species: Paracoccidoides brasiliensis (P. brasiliensis) and Paracoccidioides lutzii (P. lutzii) $)^{1}$. P. brasiliensis contains a complex of at least five phylogenetic clusters ranked as the following phylogenetic species: S1a, S1b, PS2, PS3, and PS4 2,3,4. The phylogenetic species $\mathrm{S} 1 \mathrm{a}$ and $\mathrm{S} 1 \mathrm{~b}$ are predominantly found in lower South America, especially in southeastern and southern Brazil, Argentina, and Paraguay. The PS2 species has a sporadic distribution and is less frequently reported, with human cases only being reported thus far in Venezuela and southeast Brazil (Figure 1). The PS3 and PS4 species are exclusively endemic to Colombia and Venezuela, respectively. P. lutzii encompasses a single species and is predominantly distributed in the Central West and Amazon regions of Brazil and Ecuador ${ }^{1,5,6,7,8}$. However, the real incidence of each phylogenetic species and its implication on clinical practice is difficult to establish because of the lack of guided studies comparing PCM forms and manifestations with their genetic background ${ }^{9}$. Radial immunodiffusion against the commonly used exoantigens containing a $43-\mathrm{kDa}$ glycoprotein (gp43) suggests that Paracoccidiodes spp. exhibit major antigenic variability. According to phylogenetic studies, different Paracoccidioides spp. isolates are distributed in different genotypes across multiple PCM endemic areas of Latin America. In particular, Paracoccidioides spp. in central Brazil (i.e. Mato Grosso and Rondônia) exhibit a lower rate of genetic similarity. Yet, $P$. lutzii isolates exhibit high speciesspecific antigen variability ${ }^{9}$, which has already been assessed in proteomic studies.

\section{ECOEPIDEMIOLOGY}

In nature, $P$. brasiliensis and $P$. lutzii develop as filamentous structures and produce infective propagules called conidia ${ }^{10,11}$ (Figure 2). If inhaled, the propagules give rise to yeast forms of the fungus that become parasitic to the host. Paracoccidioides spp. can cause infection and disease in humans and domestic and wild animals, although only a few active disease cases have been observed in animals, such as dogs ${ }^{10,12}$. The armadillo is known to be a reservoir of $P$. brasiliensis, and the fungus can be easily cultured from the animal's internal organs (spleen, liver, and lymph nodes), indicating a systemic process. P. lutzii has not yet been isolated from armadillos.

Epidemic outbreaks of PCM have never been observed. Further, fungal recovery (culture) directly from the fungi's environmental saprophytic form has been shown to be particularly difficult to obtain with reproducibility. Thus, the region where the disease is acquired is referred to as reservaria. Yet, sensitive molecular screening techniques have detected the fungus in soils and aerosols, especially among samples taken from animal burrows or sites with medium to high moisture content protected by vegetation cover ${ }^{13}$.

In recent decades, changes in the demographic characteristics and geographical distribution of PCM incidence have been observed. These shifts could be attributed to the rise of

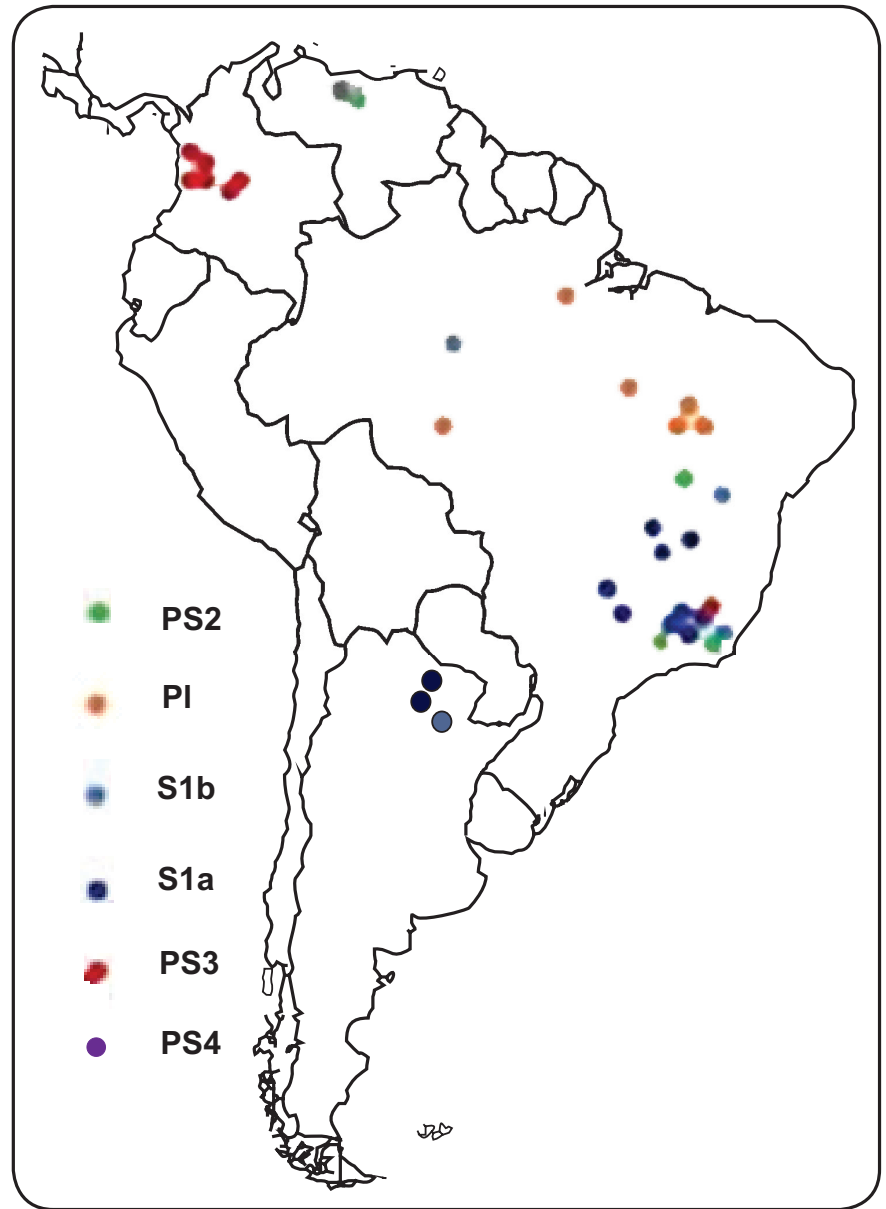

FIGURE 1 - Geographic distribution of Paracoccidioides lutzii and Paracoccidioides brasiliensis cryptic species. Modified (update on P. lutzii distribution) from: Muñoz JF, Farrer RA, Desjardins CA, Gallo JE, Sykes S, Sakthikumar S, et al. Genome diversity, recombination, and virulence across the major lineages of Paracoccidioides. mSphere 2016; 1(5): e00213-163. PS2; PS3; PS4; S1a; S1b: phylogenetic species of Paracoccidioides brasiliensis; Pl: Paracoccidioides lutzii.

urbanization, application of diagnostic methods, and the presence of comorbidities and immunosuppression. In addition, environmental factors, such as the expansion of settlements, clearing of forests, and increased coffee production, could contribute to the current high levels of PCM incidence in some regions of Rondônia ${ }^{14}$.

In addition, between 1982 and 1983, a region of Southeast Brazil experienced climatic changes related to El Niño, resulting in elevated soil moisture levels and temperatures between $18-28^{\circ} \mathrm{C}$, which are favorable for fungal sporulation and aerial dispersion. During this same time period, the region experienced an outbreak of acute cases of $\mathrm{PCM}^{15}$.

\section{How is Paracoccidioides infection acquired?}

The major risk factor for acquiring infection is a profession or activity related to the management of soil contaminated with the fungus, such as agriculture, earthworks, soil preparation, gardening, and transportation of vegetable products (Figure 2). In a majority of all PCM infection cases the patients had been exposed to agricultural activities during the first two decades of their life, at which point they likely acquired the infection even 


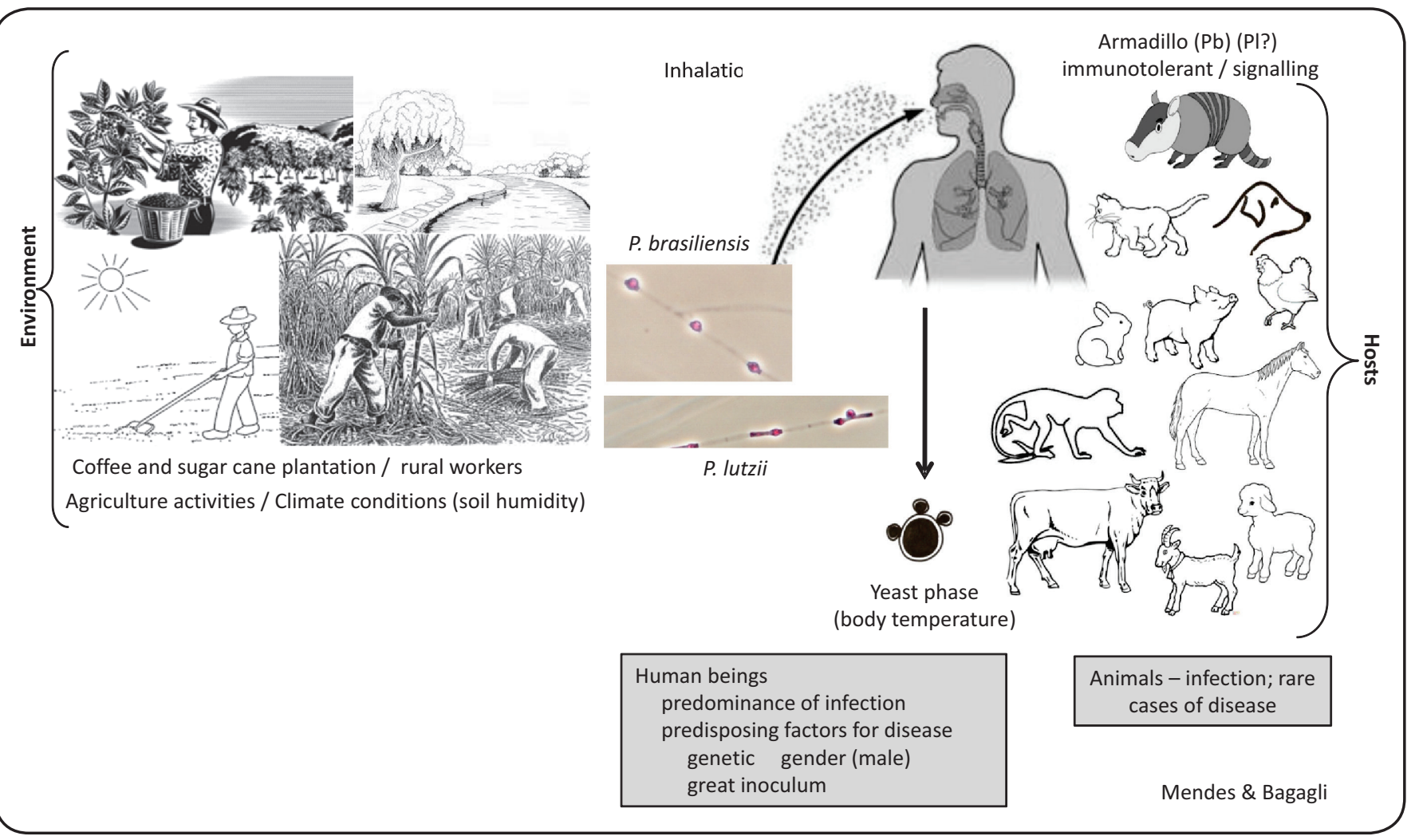

FIGURE 2 - Spread of Paracoccidioides brasiliensis and Paracoccidioides lutzii. Pb: Paracoccidioides brasiliensis; Pl: Paracoccidioides lutzii.

if clinical manifestations appeared many years later ${ }^{11}$. Most of these patients seeked medical attention many years after they left the endemic area and resided in urban centers where were engaged in other activities unrelated to soil management. For example, smoking ( $>20$ cigarettes/day for $>20$ years) and alcoholism $(>50 \mathrm{~g} / \text { day })^{16}$ are frequently associated with mycosis. Unlike other mycoses, such as cryptococcosis, disseminated histoplasmosis, and candidiasis, PCM is not usually related to immunosuppressive diseases. However, cases of PCM associated with HIV infection, neoplasia and, more rarely, organ transplants and use of immunobiologicals have been reported ${ }^{17-20}$.

\section{Incidence, prevalence and mortality}

Since PCM is not a compulsory notification disease, we do not have precise data on its incidence in Brazil. Mycosis prevalence, incidence, and morbidity estimates are based on reports from epidemiological surveys, case series, hospitalization records, and mortality data ${ }^{21}$. Based on the experiences of reference services caring for patients with PCM, the disease's incidence in endemic areas ranges from three to four new cases per one million inhabitants and one to three new cases per 100,000 inhabitants per year. About $80 \%$ of PCM cases are registered in Brazil, particularly in the States of São Paulo, Paraná, Rio Grande do Sul, Goiás, and Rondônia (Figure 3) ${ }^{21}$. In Latin America, cases are most frequently reported in Argentina, Colombia, Venezuela, Ecuador, and Paraguay. Estimates of annual incidence in Brazil range from 0.71 to 3.7 cases per
100,000 inhabitants ${ }^{21}$. However, recent records of incidence in Rondônia report 9.4 cases per 100,000 inhabitants, with two municipalities reporting incidences close to 40 cases per 100,000 inhabitants ${ }^{14}$. Between 1980 and 1995, the Ministry of Health documented 3,181 cases of PCM-related deaths, resulting in a PCM mortality rate of 1.45 cases per one million inhabitants (2.59 for the South, 2.35 for the Midwest, 1.81 for the Southeast, 1.08 for the North, and 0.2 for the northeast regions ${ }^{22}$. In this study, among all chronic infectious and parasitic disease, PCM was listed as the eighth highest cause of mortality and had the highest mortality rate among the systemic mycoses, even having a higher mortality rate than leishmaniasis. Recent data collected from 13,683 patients who were hospitalized with systemic mycoses between January 1998 and December 2006 showed that PCM accounts for the largest number of hospitalizations (49\%) among all mycoses ${ }^{23}$, with emphasis on hospitalization rates in the north and Midwest regions, without major difference in the mortality of hospitalized patients (Figure 3).

\section{Age group and distribution between genders}

PCM infection is primarily acquired in the first two decades of life, with a peak incidence between 10 and 20 years of age. However, the presentation of clinical manifestations or evolution to disease is uncommon in this age group. Instead, PCM occurs more frequently in adults between the ages of 30- and 50 -years-old as a result of endogenous latent foci reactivation ${ }^{10}$. Although the frequency of PCM cases ranges between regions, an estimated $10 \%$ of PCM cases occur in individuals under the 


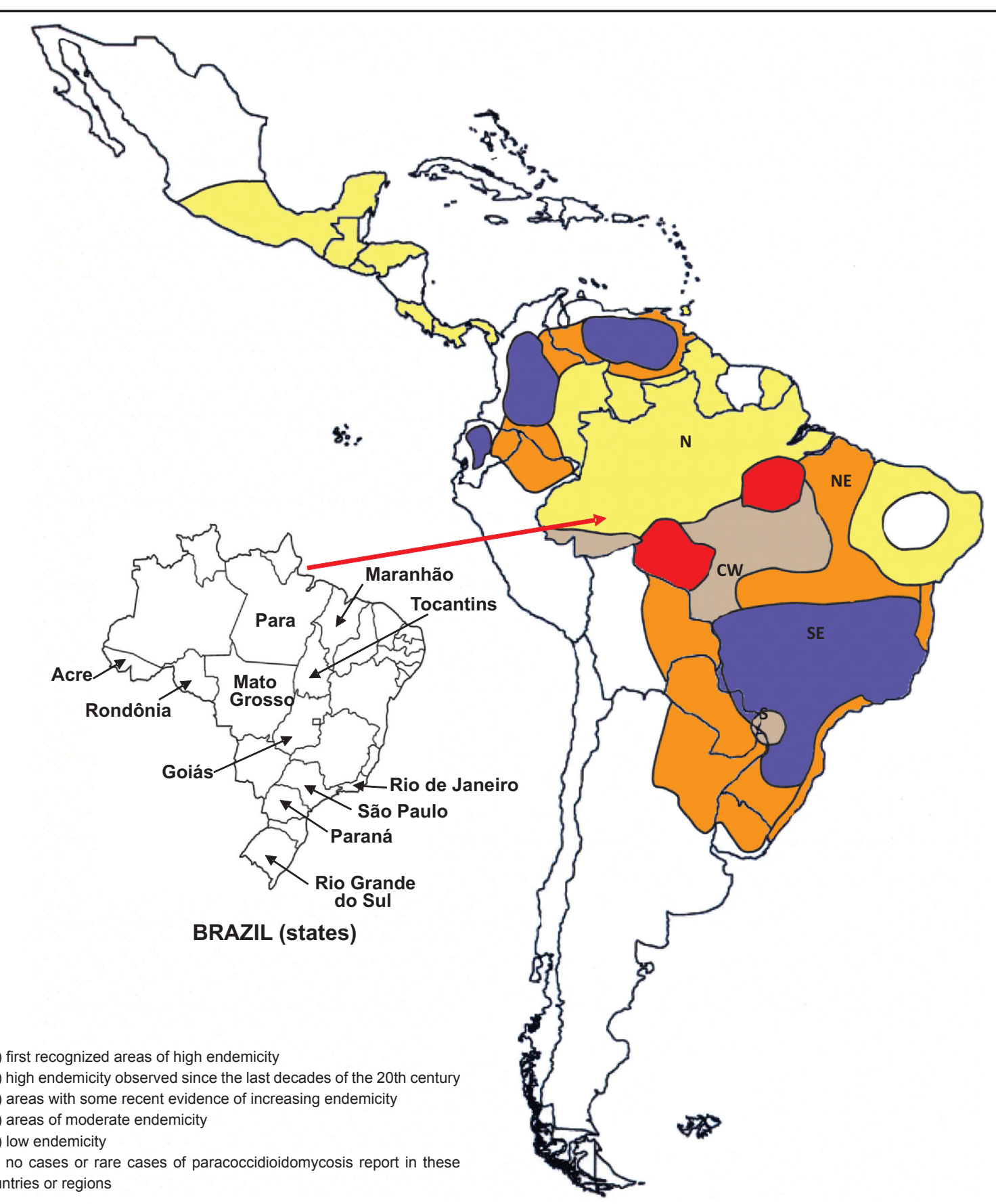

FIGURE 3 - Geographical areas of paracoccidioidomycosis endemicity in Latin America. Reproduction from: Martinez R. New trends in Epidemiology. J Fungi. 2017;3(1):121.

age of 20 -years-old, while the remaining $90 \%$ occurring later in life. Further, in childhood, the frequency of PCM cases is evenly distributed between both genders, with a slight predominance in young male adults; however, in adulthood, the frequency ranges from ten to 15 men for one woman.

\section{IMMUNOPATHOGENESIS}

Control of Paracoccidioides spp infection depends on the host's cellular immune response, with T cells playing a prominent role. PCM has a range of clinical presentations along a spectrum, with each one being potentially associated with a specific $\mathrm{T}$ cell immunity pattern ${ }^{24}$. Most infected individuals living in endemic areas will not develop any illness. These individuals exhibit a T-helper [Th-1] immune response pattern characterized by the release of cytokines that activate macrophages, $\mathrm{TCD} 4+$, and TCD8+ cells, resulting in the formation of compact granulomas and control of fungal replication ${ }^{25,26}$; however, dormant forms of the fungus may still exist inside these granulomas. The few individuals who do develop the disease most likely had deficient Th-1 responses, with the extent of the failure correlating with 
disease severity ${ }^{25,26}$. In fact, patients with infections that evolve to the more severe forms, such as the acute/subacute form disease (A) or eventually the severe disseminated chronic form (CF), develop Th-2 and Th-9 immune response patterns that do not form compact granulomas, but instead activate B lymphocytes, high levels of specific antibodies, including the the IgE subclass, hypergammaglobulinemia, and eosinophilia ${ }^{27}$. Patients with the severe/disseminated unifocal or multifocal CF who bear lower fungal burdens, also exhibit deficient Th-1 responses, often at a lesser degree that that of patients with the AF or severe disseminated CF. In addition, these patients can still experience the formation of compact granulomas that can suppress, at least partially, fungal replication ${ }^{25,26}$. In these patients, the loss of Th-1 function would be partially compensated by the development of Th-17 and Th-22 responses, both of which drive intense mucosal inflammatory responses rich in neutrophils ${ }^{27}$. In fact, a characteristic feature of the CF is the involvement of the mucosa, especially in the respiratory tract. In addition, it has been demonstrated that regulatory $\mathrm{T}$ cells (Tregs) suppress $\mathrm{T}$ cell immunity and contribute to the $\mathrm{T}$ cell anergy observed in the more severe forms of the disease ${ }^{28,29}$.

The factors that determine the different outcomes of the PCM host-parasite interaction remain unknown. Preliminary data suggest that the host's immunogenetic background may play a role $^{30}$. Regardless, clinical experiences have indicated that treatment of PCM should persist for long periods until effective cellular immune responses are elicited. However, for unknown reasons, yeast cells may remain in quiescent foci that can reactivate the disease and cause relapses. Usually, immune alterations subside with treatment and the protective Th-1 responses appear/reappear. This observation is corroborated by in vitro experiments that have demonstrated deficient Th- 1 responses can be reverted ${ }^{31}$, although this response reconstitution has not been shown to reach the magnitude of that observed in healthy individuals without disease ${ }^{32}$. The role of the observed high serum levels of specific antibodies in any mechanism of protection could not yet be determined.

\section{CLASSIFICATION OF CLINICAL FORMS AND ASSESSMENT OF SEVERITY}

PCM can compromise any organ, apparatus or system, as revealed in Table $\mathbf{1}^{33,34}$, which presents clinical and autopsy findings. Further, PCM's diversification tends to hinder its classification.

Several classifications of PCM clinical forms have been published based on different criteria, such as lesion topography, disease natural history, severity of clinical presentation, and serological reaction results. This consensus adopted the classification presented in the International Colloquium on Paracoccidioidomycosis held in February 1986 in Medellin, Colombia ${ }^{35}$.

I.Paracoccidioidomycosis infection

II.Paracoccidioidomycosis (disease)
A. Acute/subacute form (juvenile)
- Moderate
-- Severe
B. Chronic form (adult)
- - Mild
- Moderate
-- Severe
III. Residual form or sequelae

\section{Paracoccidioidomycosis infection}

Paracoccidioidomycosis infection is contracted when a healthy individual comes into contact with a Paracoccidioides spp. The infection is diagnosed by a positive intradermal reaction to specific antigens and necropsy findings of latent fungi ${ }^{36}$.

\section{Clinical forms of Paracoccidioidomycosis}

\section{Acute/subacute form (juvenile)}

The acute/subacute form of PCM is responsible for $5-25 \%$ of cases and may be more frequent in certain endemic regions while almost never observed in others. In Brazil, this form is more commonly observed in the following States: Maranhão, Minas Gerais, Pará, Goiás, and São Paulo.

The incidence of PCM appears to be declining in some endemic areas ${ }^{37}$. Acute/subacute PCM predominantly affects children, adolescents, and young adults, but can occur in adults between the ages of 30- and 40-years-old. The incidence of PCM tends to be evenly distributed between genders, especially among the adolescent population ${ }^{33,37-39}$.

This clinical form of PCM rapidly evolves and disseminates the infection to multiple organs and systems. In general, patients are diagnosed within a few weeks of symptoms onset. Most symptoms involve the phagocytic-mononuclear system, including the presence of localized or generalized lymphadenomegaly, which may present suppuration, fistulization, and hepatosplenomegaly. Symptoms may also include digestive manifestations, cutaneous (or mucosal) lesions, osteoarticular involvement, and rarely, pulmonary involvement. Fever, weight loss, and anorexia often accompany the clinical presentation. Intra-abdominal lymphadenomegaly may coalesce, producing tumor masses that exert compression on various organs, such as the bile duct and intestinal loops ${ }^{38}$ (Figure 4 and Figure 5). A prominent finding of laboratory alterations in this form is peripheral eosinophilia, which occurs in $30 \%$ to $50 \%$ of cases $^{38-40}$. Under certain conditions, eosinophilia may be significant (up to $70 \%$ of peripheral blood leukocytes).

\section{Chronic form (adult)}

The majority ( $74 \%$ to $96 \%$ ) of PCM cases are in chronic form, which typically manifests in adults between the ages of 30- and 60-years-old (male to female ratio: 22:1). Chronic PCM initiates slowly and the symptoms often persist beyond 4 to 6 months, possibly even a year. In some cases, PCM develops without any physical indication, and the infection is only caught when the individual goes for a routine check-up or labor-related physical examinations. In $90 \%$ of patients with PCM, pulmonary impairment is observed ${ }^{41,42}$. After the lungs, the organs most affected by PCM are the mucosa of the upper aerodigestive pathway and skin (Figure 6 and Figure 7). 
TABLE 1

Organs affected in paracoccidioidomycosis.

\begin{tabular}{|c|c|c|c|c|c|c|}
\hline \multirow[t]{3}{*}{ Organs } & \multicolumn{4}{|c|}{ Clinical manifestation } & \multirow{2}{*}{\multicolumn{2}{|c|}{$\begin{array}{c}\text { Necropsies } \\
\text { Franco et al }[34]^{* * *}\end{array}$}} \\
\hline & \multicolumn{2}{|c|}{$\begin{array}{l}\text { Belissimo-Rodrigues } \\
\text { et al [33]* }\end{array}$} & \multicolumn{2}{|c|}{ Franco et al $[34]^{* *}$} & & \\
\hline & $\mathbf{n}$ & $\%$ & $\mathbf{n}$ & $\%$ & n & $\%$ \\
\hline Lungs & 778 & 63.8 & 128 & 74.0 & 24 & 96.0 \\
\hline Bronchus/trachea & 5 & 0.4 & 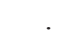 & . & . & \\
\hline Lymphadenomegaly & 618 & & 63 & 36.4 & 18 & 72.0 \\
\hline generalized & 342 & 28.1 & & & & \\
\hline localized & 276 & 22.6 & & & & \\
\hline Mouth, pharynx, larynx & & & 83 & 48.0 & 15 & 60.0 \\
\hline oral mucosa & 610 & 50.0 & & & & \\
\hline larynx & 196 & 16.1 & & & & \\
\hline nasal mucosa & 19 & 1.6 & & & & \\
\hline Adrenals & 26 & 2.1 & 6 & 3.5 & 11 & 44.0 \\
\hline Central Nervous System (CNS) & 42 & 3.4 & 1 & 0.6 & 9 & 36.0 \\
\hline Liver & & & 0 & 0.0 & 8 & 32.0 \\
\hline Spleen & 57 & 4.7 & 0 & 0.0 & 7 & 28.0 \\
\hline Skin & 361 & 29.6 & 22 & 12.7 & 6 & 24.0 \\
\hline Kidney & & & 0 & 0.0 & 4 & 16.0 \\
\hline Bone marrow & & & 0 & 0.0 & 3 & 12.0 \\
\hline Heart & & & 0 & 0.0 & 3 & 12.0 \\
\hline Digestive tract & 92 & 7.5 & 6 & 6.5 & 2 & 8.0 \\
\hline Testicles & 9 & 0.7 & 1 & 0.6 & 2 & 8.0 \\
\hline Prostate & & & 1 & 0.6 & 2 & 8.0 \\
\hline Eyes & & & 2 & 1.2 & 0 & 0.0 \\
\hline Breast & & & 1 & 0.6 & 0 & 0.0 \\
\hline
\end{tabular}

Osteoarticular

*1,219 patients of the Faculdade de Medicina de Ribeirão Preto, Universidade de São Paulo (USP). ** 173 patients and 25 necropsies at the Faculdade de Medicina de Botucatu, Universidade Estadual Paulista (UNESP).

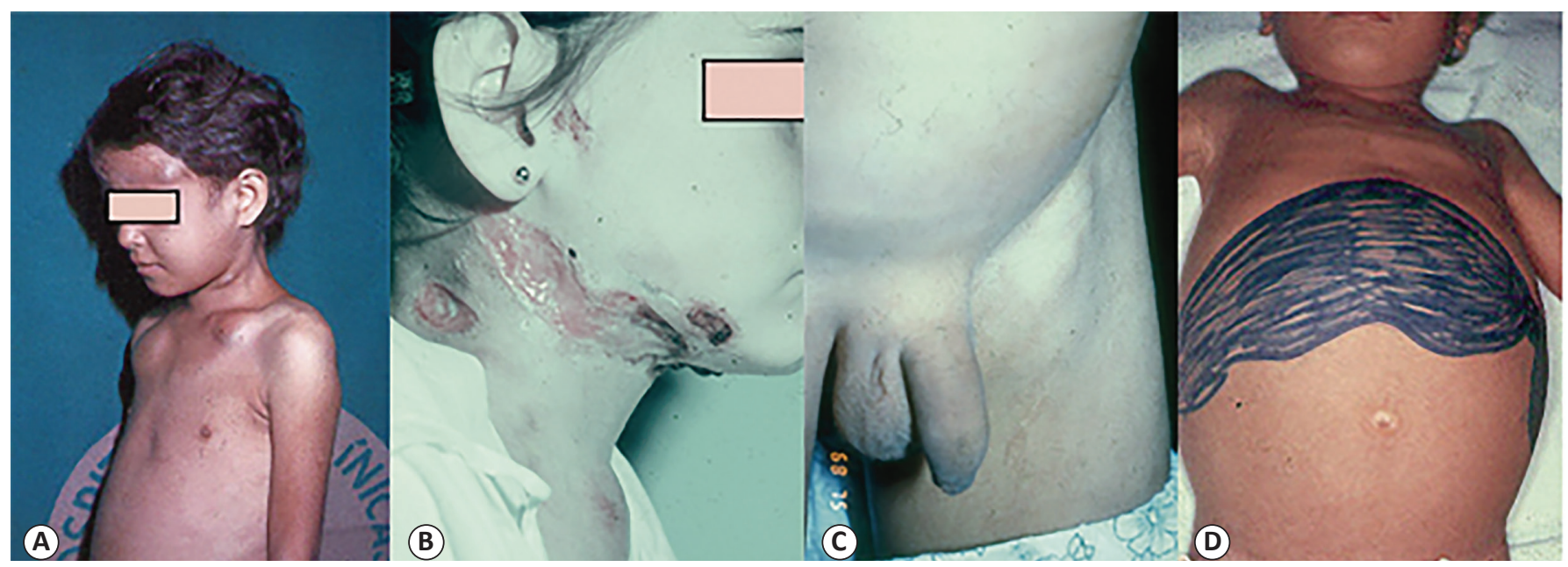

FIGURE 4 - Acute form of PCM in children. A. Abscesses in frontal and clavicular regions resulting from osteo-articular involvement. B. Female child presenting with abscessed lymphatic involvement. C. Inguinal lymphoadenomegaly. D. Lymphatic-abdominal involvement with ascites and hepatosplenomegaly. PCM: paracoccidioidomycosis. Reproduction with modification: Shikanai-Yasuda MA, Telles Filho F de Q, Mendes RP, Colombo AL, Moretti ML, Grupo de Consultores do Consenso em Paracoccidioidomicose. Consenso Brasileiro em Paracoccidioidomicose. Rev Soc Bras Med Trop. 2006;39(3):297-310². 

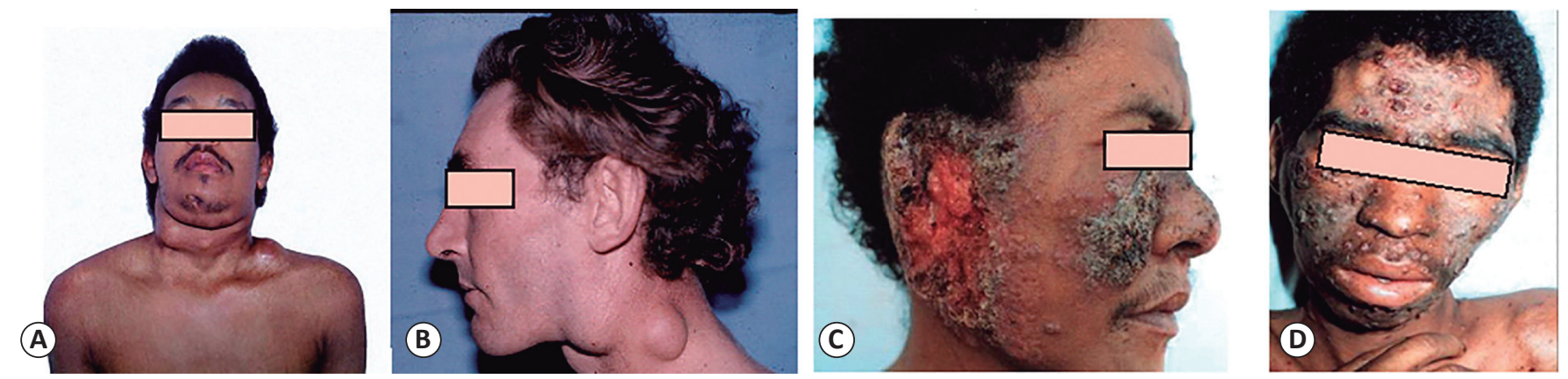

FIGURE 5 - Patients with the acute/subacute (juvenile) form of PCM. A. Ganglionic mass in supraclavicular, cervical, and submandibular region. B. Lymphadenomegaly of PCM, which must be differentiated from hematological diseases, such as lymphoma. C. Verrucous ulcerative lesions on the face and pavilion caused by hematogenous dissemination. D. Papulonodular ulcerative lesions caused by hematogenous dissemination. PCM: paracoccidioidomycosis. Reproduction with modification: Shikanai-Yasuda MA, Telles Filho F de Q, Mendes RP, Colombo AL, Moretti ML, Grupo de Consultores do Consenso em Paracoccidioidomicose. Consenso Brasileiro em Paracoccidioidomicose. Rev Soc Bras Med Trop. 2006;39(3):297-310.

Chronic PCM can be classified as either mild, moderate, or severe $^{35}$. Severe cases are defined by meeting three or more of the following criteria: a) weight loss greater than $10 \%$ of the normal body weight; b) intense pulmonary involvement; c) involvement of other organs, such as adrenal glands, central nervous system, and bones; d) the presence of lymph nodes affected in multiple chains in superficial or deep, pseudotumoral form $(>2.0 \mathrm{~cm}$ in diameter, without suppuration) or suppurative form; e) high antibody titers.

In fact, severe cases are represented by patients presenting clinical instability due to respiratory insufficiency, adrenal dysfunction, neurological syndrome or acute abdomen.

Mild cases, which constitute a small portion of patients, are those with weight loss below $5 \%$ of normal body weight and involvement of unique or a few organs or tissues without disfunction.

In some cases, patients present with clinical manifestations of both acute/subacute and chronic forms, making it difficult to properly classify the disease. Most of these patients present with intense suppression of cellular immunity and are labelled as having mixed form $\mathrm{PCM}^{43}$.

\section{Residual forms (sequelae)}

Residual forms, also referred to as sequelae, are clinical manifestations of anatomical and functional changes observed
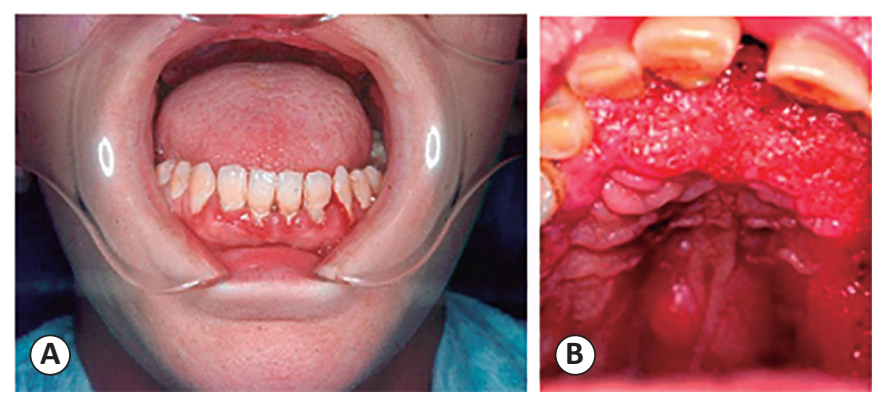

FIGURE 6 - Oral involvement in chronic PCM 47,48. A. Gingivostomatitis. B. Moriform stomatitis of Aguiar-Pupo. The lesions may present as extensive, ulcers, or ulcer-vegetative, with characteristic hemorrhagic dots (moriform lesion). Although infrequent, the lesions may extend into the nasal vestibule, causing perforation of the palate and nasal septum, with inaesthetic and functional sequelae. In acute PCM, the oral mucosa is not frequently involved. PCM: paracoccidioidomycosis. Reproduction with modification: ShikanaiYasuda MA, Telles Filho F de Q, Mendes RP, Colombo AL, Moretti ML, Grupo de Consultores do Consenso em Paracoccidioidomicose. Consenso Brasileiro em Paracoccidioidomicose. Rev Soc Bras Med Trop. 2006;39(3):297-310 ${ }^{39}$.

after PCM treatment. Sequelae are observed in multiple organs, but have a higher rate of incidence in the lungs, skin, larynx, trachea, adrenals, mucosa of the upper aerodigestive tract, central nervous system, and lymphatic system, thus explaining the diversity of clinical presentation ${ }^{44-46}$.
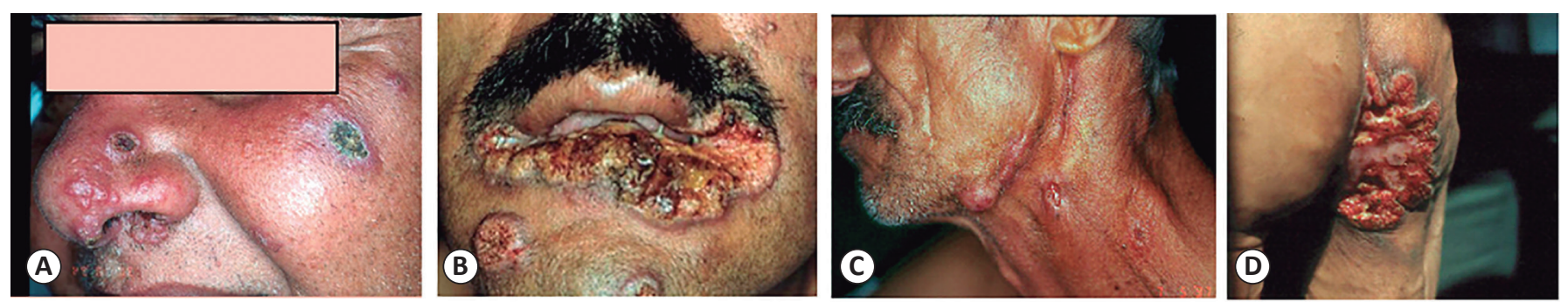

FIGURE 7 - Clinical aspects of chronic PCM. A. Papulonodular ulcerative lesions on the face. B. Perioral and mentonian involvement. C. Fistulated cervical and submandibular lymph nodes. D. Vegetative lesion with irregular borders in the perianal region. Through hematogenous dissemination, especially traumatic fungal implantation, the cutaneous lesions contiguously develop from compromised mucosa, fistulated lymph nodes, or bone involvement ${ }^{47}$. The lesions are characterized by ulcero-crusted polymorphisms, molluscoids, papules, or acneiforms, and are located primarily in the cephalic pole and periorificial regions ${ }^{48}$. Of note, patients with Addison's syndrome typically present with cutaneous and mucosal hyperpigmentation. PCM: paracoccidioidomycosis. Reproduction with modification: Shikanai-Yasuda MA, Telles Filho FQ, Mendes RP, Colombo AL, Moretti ML, Grupo de Consultores do Consenso em Paracoccidioidomicose. Consenso Brasileiro em Paracoccidioidomicose. Rev Soc Bras Med Trop. 2006;39(3):297-310. 


\section{INITIAL TREATMENT, DIAGNOSTIC APPROACH, AND OUTPATIENT FOLLOW-UP ROUTINE OF PATIENTS WITH PCM}

Since PCM is systemic, any organ can be affected. The attention of the observer should initially be directed to the general condition of the patient and then the organs and systems that are most frequently committed according to the forms of the disease presentation: acute/subacute PCM and chronic PCM. According to routine medical care, all patients should have a detailed physical examination, reporting weight and height evaluation, to allow the characterization of nutritional status.

\section{General evaluation of a patient with acute/subacute form}

In acute/subacute PCM, anamnesis and physical examination play an important role in the determination of disease severity and systemic involvement. For example, the presence of lymphadenomegaly in various lymphatic chains, hepatosplenomegaly, cutaneous lesions, or abdominal masses can be confirmed during a patient's physical examination. In addition, clinical examination can also detect the presence of jaundice, ascites, and peripheral edema, which prompt investigation of hypoalbuminemia. In acute/subacute PCM, signs of adrenal and neurological involvement are rare. Fever, weight loss, and digestive complaints, such as abdominal pain, chronic malabsorptive diarrhea, and vomiting, are also quite frequen $t^{40}$. The presence of tumefaction or pain in the bone region requires the identification of bone lesions.

\section{Laboratory tests and imaging:}

Chest X-ray (posterior, anterior, profile)

Complete blood count and erythrocyte sedimentation rate (ESR)

Liver biochemical tests (alanine aminotransferase (ALT), alkaline phosphatase)

Total proteins and fractions

Evaluation of renal and metabolic function (serum creatinine, $\mathrm{Na}, \mathrm{K}$ )

Imaging tests, such as ultrasound, CT, magnetic resonance imaging (MRI), and scintigraphic mapping should only be performed when there is clinical suspicion or laboratory results suggestive of organ involvement that cannot be solely assessed by physical examination.

\section{General evaluation of a patient with chronic form}

In chronic PCM, anamnesis and physical examination must include the evaluation of signs and symptoms related to pulmonary, tegumentary, and laryngeal involvement ${ }^{41,46}$ (cough, dyspnea, mucus/purulent expectoration, ulcerated lesions of the skin and naso-oropharyngeal mucosa $a^{47,48}$, odynophagia, dysphagia, and dysphonia). Both diagnostic methods must also evaluate signs and symptoms of lymphatic adenomegaly, adrenal involvement ${ }^{49,50}$ (asthenia, weight loss, hypotension, skin darkening, abdominal pain), central nervous system involvement ${ }^{51,52}$ (headache, motor deficit, convulsive syndrome, and alteration of behavior and/or level of consciousness), and digestive impairment (diarrhea and malabsorption syndrome $)^{53,54}$ (Figure 8).
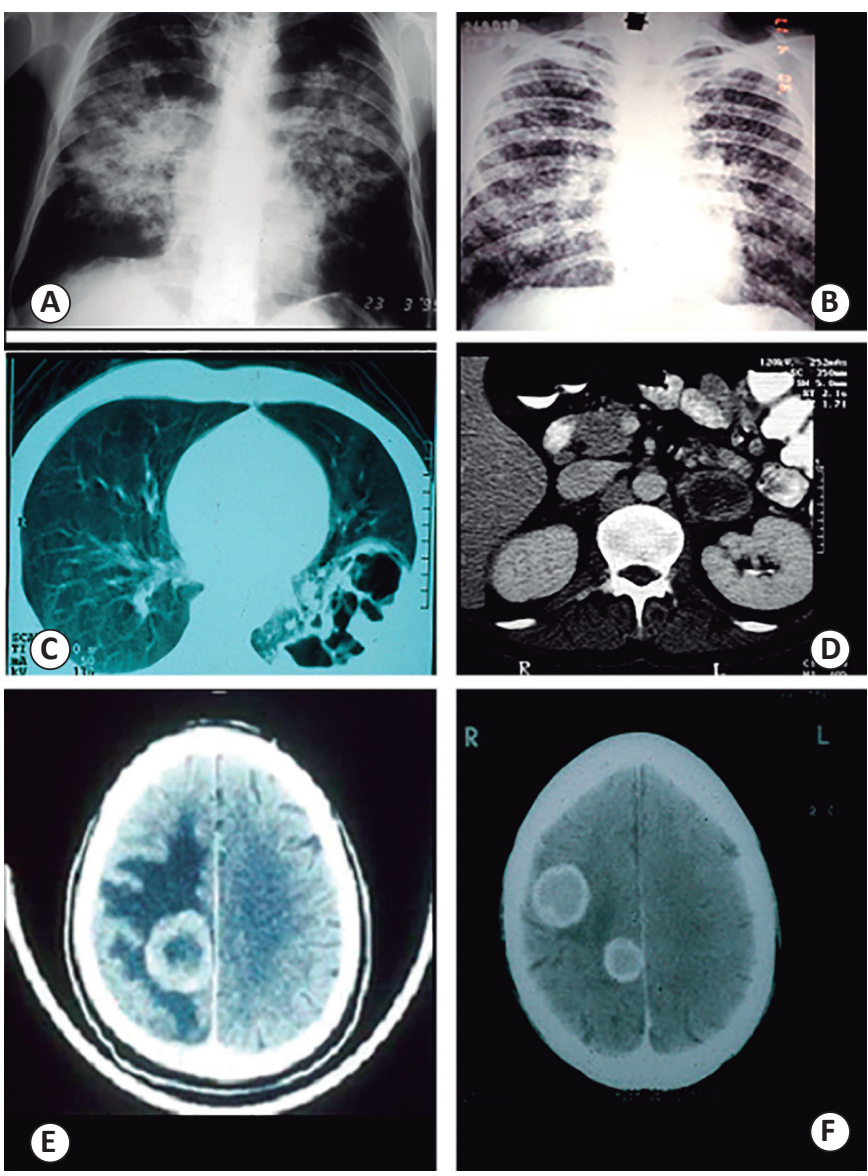

FIGURE 8 - Images of PCM. A. Conventional butterfly wing radiological image showing bilateral, parahilar, and symmetrical pulmonary involvement with a predominance of alveolar lesions, sparing apices and lower thirds. These manifestations are very suggestive of PCM but occur infrequently. B. Diffuse and symmetric nodular and micronodular opacities. C. Computed tomography $(\mathrm{CT})$ of lungs with multiple sub-pleural cavities. Pulmonary lesions may be interstitial of the thin or coarse reticular-nodular type, or, less frequently of the tumor type. D. Bilateral adrenal increase. E and F. CNS: hypodense and ring-shaped contrast enhancement images with small mass effect. PCM: paracoccidioidomycosis. Reproduction with modification: Shikanai-Yasuda MA, Telles Filho F de Q, Mendes RP, Colombo AL, Moretti ML, Grupo de Consultores do Consenso em Paracoccidioidomicose. Consenso Brasileiro em Paracoccidioidomicose. Rev Soc Bras Med Trop. 2006; 39(3): 297-310 ${ }^{39}$.

\section{Laboratory tests and imaging}

Chest $X$-rays (posterior, anterior, profile)

Complete blood count and erythrocyte sedimentation rate (ESR)

Liver biochemical tests (ALT, alkaline phosphatase)

Evaluation of renal and metabolic function (serum creatinine, $\mathrm{Na}, \mathrm{K}$ )

More complex examinations should be conducted if there is a clinical suspicion or laboratory result suggesting central nervous system involvement, gastrointestinal involvement, abdominal forms, chronic respiratory insufficiencies, or osteo-articular lesions. In patients presenting with these signs, 
imagining and functional tests should be performed under the guidance of medical experts. Given the high frequency of adrenal involvement and its clinical impact, patients suspected of having chronic PCM should undergo an assessment of the functional reserve when available.

\section{Differential diagnosis}

Other conditions to consider in the differential diagnosis for PCM include the following: acute lymphoma, leukemia, histoplasmosis, tuberculosis, toxoplasmosis, visceral leishmaniasis, and infectious mononucleosis. For chronic cutaneous-mucosal PCM, the conditions to consider in the differential diagnosis are cutaneous or mucosal leishmaniasis, tuberculosis, chromoblastomycosis, leprosy, sarcoidosis, lues, neoplasia and in the chronic pulmonary form, tuberculosis $\left(\right.$ Table 2) ${ }^{55}$, coccidioidomycosis, histoplasmosis, sarcoidosis, pneumoconiosis, and interstitial pneumonitis. For digestive
PCM, conditions to consider in the differential diagnosis are tuberculosis and Chron's disease, while for forms of PCM that affect the central nervous system, the conditions are tuberculosis, cryptococcosis, cysticercosis, and neoplasias.

\section{Laboratory examinations for specific diagnosis}

The identification of Paracoccidioides spp. through the examination of fresh sputum or other clinical specimens, such as lesion sample, lymph node aspiration, or biopsy fragment, is the gold standard for PCM diagnosis.

Aspects of PCM laboratory diagnosis are presented in Figure 9.

In an attempt to standardized PCM diagnosis, the following definitions are offered:

Suspected case: patient presents with one or more of the following manifestations, excluding tuberculosis and other

TABLE 2

Pulmonary involvement: differences between tuberculosis and paracoccidioidomycosis*.

\begin{tabular}{|c|c|c|}
\hline Epidemiology & Tuberculosis & Paracoccidioidomycosis \\
\hline Age & Wide range & Restricted (30- to 60-years-old) \\
\hline Gender & Indistinct & Prevalent in males $(15: 1)^{* *}$ \\
\hline Mortality & $2.3 / 100,000$ & $1.65 / 1,000,000$ \\
\hline Geographic distribution & Worldwide, more urban & Latin America, more rural \\
\hline \multicolumn{3}{|l|}{ Microbiology } \\
\hline infection & Contagious & Non-contagious \\
\hline cultivation & Fastidious & Fastidious \\
\hline \multicolumn{3}{|l|}{ Clinical aspects } \\
\hline signs and symptoms & Well defined & Non-specific \\
\hline weight loss & $++/++++$ & $++/++++$ \\
\hline association & PCM $(10-15 \%)$ & TB $(10-15 \%)$ \\
\hline \multicolumn{3}{|l|}{ Radiology } \\
\hline image localization & Predominance in upper zone & $\begin{array}{c}\text { Predominance in medium thirds, bilateral, and } \\
\text { diffuse zones }\end{array}$ \\
\hline cavities & $+++/++++$ & $++/++++$ \\
\hline pleural images & Yes & No \\
\hline dissemination & Uni/multifocal & Uni/multifocal \\
\hline \multicolumn{3}{|l|}{ Laboratorial changes } \\
\hline red cells & Normocytic normochromic anemia & Normocytic normochromic anemia \\
\hline white cells & Leukocytosis/leukopenia & Leukocytosis/leukopenia \\
\hline ESR & $+++/++++$ & $+/++$ \\
\hline
\end{tabular}

* Modified from: Queiroz-Telles F and Escuissato D. Pulmonary paracoccidioidomycosis. Semin Respir Crit Care Med. 2011;32:764-745.**Pneumonia may occur rarely in acute/subacute PCM. In these cases, both sexes can be affected; ***Fever may occur in patients with associated infections. PCM: paracoccidioidomycosis; TB: tuberculosis; ESR: erythrocyte sedimentation rate. 
diseases that occur with a similar condition, for at least four weeks:

- Cough with or without sputum and dyspnea

- Sialorrhea, odynophagia, or hoarseness

- Lesion (ulcerated) in the nasal or oral mucosa

- Skin lesions (ulcers, vegetation, nodules, plaques, etc.)

- Cervical or generalized adenomegaly, with or without suppuration and fistulization.

- Child or young adult with hepatosplenomegaly and/or abdominal tumefaction

Probable case: a patient with clinical manifestations compatible with PCM and anti-P. brasiliensis/P. lutzii serum antibody titers detected preferably by quantitative double immunodiffusion test or counterimmunoelectrophoresis.

Confirmed case: Patient with clinical manifestations compatible with PCM with secretions, bodily fluids, or lesion material presenting with fungal elements suggestive of $P$. brasiliensis/P. lutzii infection (Figure 9). Note, the micromorphology of $P$. brasiliensis/P. lutzii parasitic forms in the biological material of infected patients cannot distinguish between the two species. Therefore, the identification of the involved species requires culture isolation and application of molecular techniques ${ }^{56,57}$.
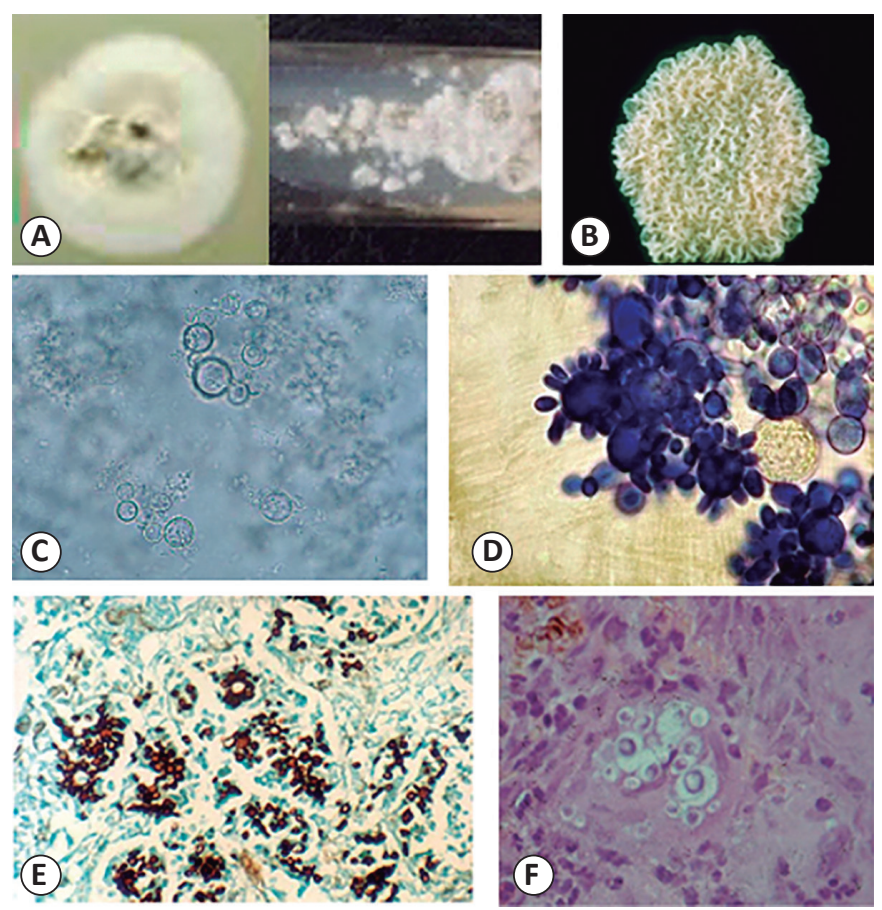

FIGURE 9 - Laboratory diagnosis of paracoccidioidomycosis. A and B. Cultivation of $P$. brasiliensis. A. mycelial phase. B. yeast phase. C. Fresh examination in $\mathrm{KOH}$. D. Lactophenol staining showing yeast cells with multiple buds. E. Histological section stained by the Grocott method. F. Histological section stained by PAS. KOH: Potassium hydroxide; PAS: Periodic acid - Schiff stain. Reproduction with modification: Shikanai-Yasuda, MA, Telles Filho F de Q, Mendes RP, Colombo AL, Moretti ML, Grupo de Consultores do Consenso em Paracoccidioidomicose. Consenso Brasileiro em Paracoccidioidomicose. Rev Soc Bras Med Trop. 2006;39(3):297-310 39 .

\section{Critical evaluation of serological tests: serologic diagnosis and follow-up}

Specific serological tests are important in not only the diagnosis of PCM, but also in the assessment of host response to specific treatments. Currently, double immunodiffusion (DID), counterimmunoelectrophoresis (CIE), immunoenzymatic assays (ELISA), and immunoblots (IB) are the serological tests available in different reference services ${ }^{58-60}$.

These tests use standardized techniques and adequate antigens ${ }^{61}$, and display a sensitivity between $80 \%$ and $95 \%$. The titer of specific anti- $P$. brasiliensis antibodies ${ }^{58,59,60}$ correlates with the severity of the clinical forms, with higher levels detected in the acute/subacute and disseminated forms. In cases of PCM caused by P. lutzii, such information remains unknown, which has motivated multicenter studies in endemic areas. PCM cases with false negative results from any of the previously mentioned tests are most often associated with very localized lesions and hosts with AIDS or immunodepressive conditions. Antigens prepared from P. brasiliensis that are rich in gp43KDA ${ }^{62}$ have excellent accuracy in the diagnosis of $P$. brasiliensis infections ${ }^{58-60}$, but have a low sensitivity in the diagnosis of $P$. lutzii infections ${ }^{63,64}$. These serological tests display a specificity between $85 \%$ and $100 \%$, with immunodiffusion having the highest rate of specificity. False-positive reactions may occur in sera from patients with histoplasmosis, and eventually aspergillosis and leishmaniasis; however, gel immunodiffusion provides the highest rate of specificity for these conditions.

Currently, the main method of PCM serological diagnosis is double agar gel immunodiffusion (DID) because of its simplicity, cost-effectiveness, sensitivity $(>80 \%)$, specificity $(>90 \%)$, and extensive application over the last decades. For DID, or any other test used in the diagnosis of PCM, serums should be titrated to increase the accuracy of therapeutic response interpretation because antibody titers progressively decrease with successful clinical control. To meet serological cure criteria, negative or stabilization results at a dilution of 1:2 or less should be achieved. In certain cases, patients may already have titers below 1:4 upon diagnosis; therefore, the serological criteria will have limited value during treatment follow-up. Additional resources and techniques for PCM diagnosis have been developed, but they are not available for PCM routine assessment. These examinations include the immunoblot technique, the triage ELISA test, the detection of specific antigens and $\mathrm{PCR}^{65,66}$.

To date, there are no validated serological techniques for the accurate diagnosis of infection by $P$. lutzii. Unfortunately, there is no commercial system available for PCM diagnosis, and all available tests are based on systems developed in hous $e^{58-60,63,64}$. A recent study revealed a large variability in the mycosis diagnostic results generated by serological tests performed at different reference laboratories ${ }^{67}$. Thus, to ensure precise assessment, follow-up serological response curves to antifungal treatments should be performed by the same technique and laboratory. 


\section{Frequency of outpatient visits and completion of examinations}

During the first 3 months of infection, monthly consultations are recommended to optimize patient adherence to the established regimen, to assess drug tolerability, and to ensure good clinical response (Table 3). If a satisfactory clinical response is observed, the consultations should become quarterly until the end of the first year. After 90 days of followup if a satisfactory clinical response is observed, patients should undergo complete blood count and biochemical tests every 3 months during the first year. Radiological and serological examinations should be requested every 6 months, or at shorter intervals if a satisfactory clinical response is not observed or if laboratory results indicate no change in activity. The reduction of specific antibody titers should occur approximately 6 months after treatment and should be either negative or stabilized at low titers for approximately 10 to 24 months after treatment. These estimations depend on the clinical form, severity, and antifungal treatment administered, as itraconazole promotes a faster response than cotrimoxazole in the acute form rather than the chronic form. In the second year of follow-up, the consultations should become semi-annual. Once the cure criteria have been met, treatment should be discontinued and patients should be followed-up on an outpatient basis for up to two years. After this period, if the patient continues to meet cure criteria, the patient can be released from outpatient followup and instructed to return if necessary.

According to the clinical presentation of PCM, specific followup examinations, such as ultrasound (e.g. to evaluate the evolution of nodal masses or nodular images in abdominal organs), and CT, or MRI to evaluate cephalic lesions should be requested.

\section{Clinical specialty outpatient support}

Patients with PCM that involves the larynx (dysphonia) and trachea should be referred to an otorhinolaryngologist

TABLE 3

Guidance for clinical-laboratory follow-up of patients with paracoccidioidomycosis undergoing therapy.

\begin{tabular}{|c|c|c|c|c|c|c|}
\hline Examinations & $\begin{array}{c}1^{\text {st }} \text { medical } \\
\text { appointment }\end{array}$ & $\begin{array}{c}1^{\text {st }}, 2^{\text {nd }} \\
3^{\text {rd }} \text { month }\end{array}$ & $\begin{array}{c}6^{\text {th }}, 9^{\text {th }} \\
12^{\text {th }} \text { monh }\end{array}$ & $\begin{array}{c}18^{\text {th }}, \\
24^{\text {th }} \\
\text { month }\end{array}$ & $\begin{array}{l}\geq 2 \text { years } \\
6 / 6 \text { months }\end{array}$ & $\begin{array}{c}>1 \text { year after } \\
\text { treatment } \\
\text { interruption: } 6 / 6 \\
\text { months* }\end{array}$ \\
\hline $\begin{array}{l}\text { Medical } \\
\text { appointment }\end{array}$ & $\mathrm{X}$ & $\mathrm{X}$ & $\mathrm{X}$ & $\mathrm{X}$ & $\mathrm{X}$ & $\mathrm{X}$ \\
\hline $\begin{array}{l}\text { Hemogram, } \\
\text { ALT, Alkaline } \\
\text { phosphatase }\end{array}$ & $\mathrm{X}$ & $3^{\text {rd }}$ month & $\mathrm{X}$ & $\mathrm{X}$ & $\mathrm{X}$ & $\mathrm{X}$ \\
\hline $\mathrm{Na}, \mathrm{K}$ creatinine & & & & & & \\
\hline
\end{tabular}

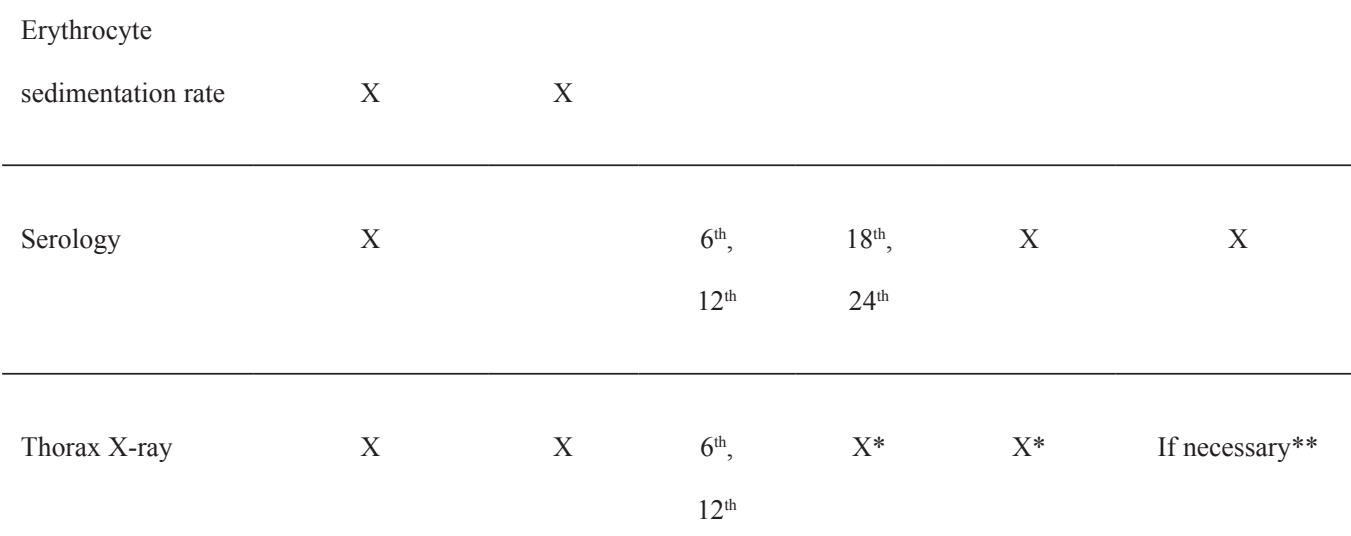

ALT: alanine aminotransferase; Na: sodium; K: potassium. * After 1 year of treatment discontinuation, the patient should be released from follow-up if cure criteria has been met. **Thorax X-ray: according to the presence of changes. 
for evaluation and specialized examinations, such as nasofibroscopy, for early diagnosis and treatment of complications.

Despite adequate treatment and satisfactory therapeutic response, patients who develop persistent dyspnea associated with cutaneous and mucosal lesion scarring and body weight recovery should be referred to a pulmonologist to treat cicatricial lung disease or associated respiratory pathologies.

Similarly, patients with Addison's syndrome caused by adrenal impairment as a result of active or residual PCM should be followed up by an endocrinologist, especially those patients who were unresponsive to usual treatments. Patients with PCM with neurological, intestinal, or abdominal lymphatic involvement, accompanied by malabsorption syndromes, reproductive organ lesions, or other clinical situations, should be followed-up by a specialized physician because management of disease in these patients often presents additional difficulties.

\section{INDICATIONS FOR HOSPITALIZATION}

The following types of patients must be hospitalized:

1. Patients with disseminated forms presenting one of the following complications: neurological alterations, respiratory insufficiency, nutritional status deficiency, gastrointestinal involvement, jaundice, ascites, or hemodynamic changes.

- Patients presenting comorbidities, such as AIDS, tuberculosis, and/or neoplasia, and if there is a need for better diagnostic investigation or observed clinical deterioration.

- Patients with sequelae and clinical instability, such as decompensated COPD, cor pulmonale, Addison's disease, laryngeal, or tracheal stenosis (Figure 10).

\section{ASSESSMENT OF COMORBIDITIES AND IMMUNOSUPPRESSION}

Many patients with chronic PCM are smokers and present with chronic obstructive pulmonary disease (COPD) prior to the diagnosis of mycosis. Other diseases are relatively common in patients with PCM, particularly chronic infectious parasitic diseases and neoplasias. Predisposing factors of PCM are believed to promote the occurrence of certain diseases, including tuberculosis, leishmaniasis, Chagas disease, leprosy, and strongyloidiasis ${ }^{33}$. Further, Paracoccidioides spp. may be opportunistic in patients with reduced cellular immunity as a result of underlying disease or immunosuppressive treatments.

\section{Tuberculosis}

Tuberculosis has been reported in approximately $2 \%$ to $20 \%$ of PCM cases, and the disease can be diagnosed before, after, or concurrently with PCM. When the two infections occur simultaneously, difficulties may arise in the diagnosis, selection of antifungal therapy, and recognition of therapeutic response ${ }^{68}$. In patients with lung injuries related to Paracoccidioides spp.
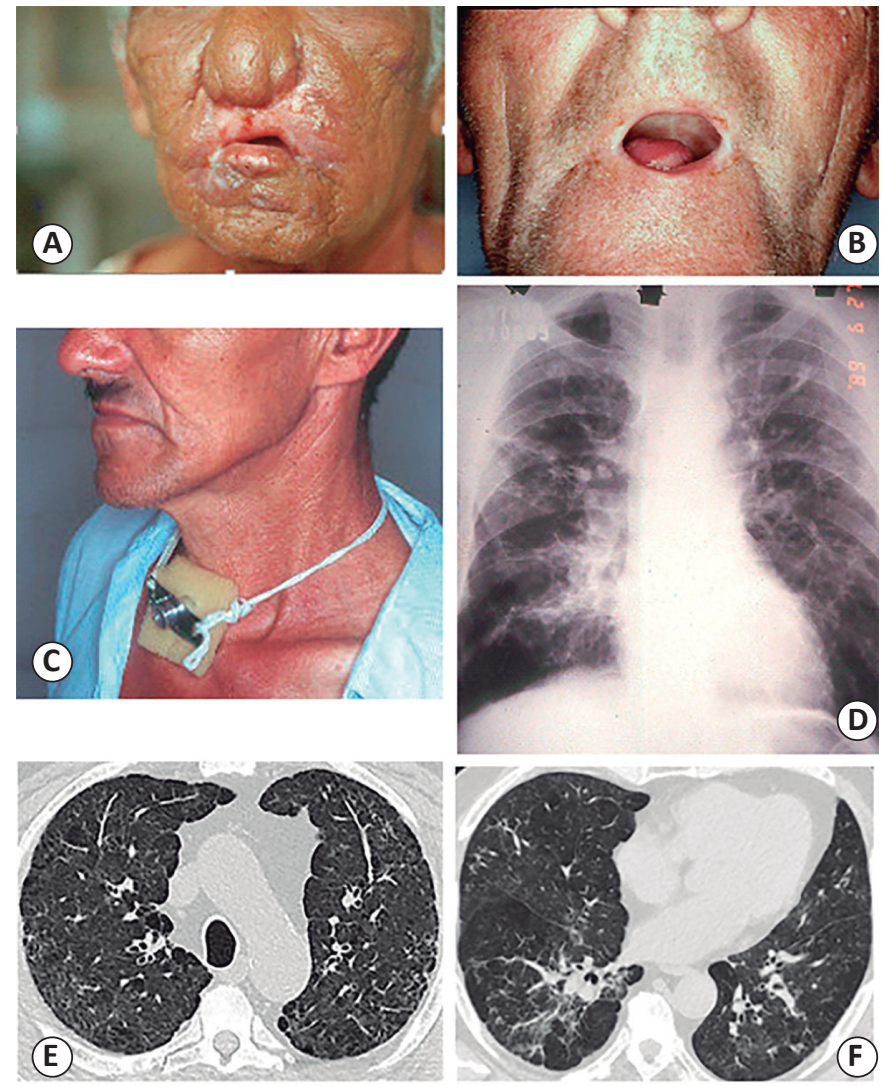

FIGURE 10 - Sequelae of PCM in the respiratory system. A and B. Microstomia resulting from perioral lesions. C. Tracheostomy as a result of tracheal stenosis. D. Chest X-ray showing residual bilateral reticular infiltrate. E and F. CT showing post-treatment septal thickening, peripheral reticulation, and peribroncovascular thickening. PCM: paracoccidioidomycosis. Reproduction with modification: Shikanai-Yasuda, MA, Telles Filho F de Q, Mendes RP, Colombo AL, Moretti ML, Grupo de Consultores do Consenso em Paracoccidioidomicose. Consenso Brasileiro em Paracoccidioidomicose. Rev Soc Bras Med Trop. 2006;39(3):297-310 .

infection, sputum smear microscopy is recommended to evaluate the occurrence of tuberculosis, especially when there is pulmonary infiltrate affecting the upper lobes.

\section{Cancer}

Several studies have reported that between $0.16 \%$ and $14.1 \%$ of patients with PCM also present with a neoplasm at some point in their lives ${ }^{19}$. Carcinomas were observed more frequently in the lungs, oropharynx, and larynx. Patients with Paracoccidioides spp.-related airway lesions may develop carcinomas at or near the fungal lesion several years later ${ }^{19}$. Whether PCM represents a risk factor for cancer or if both diseases have similar predisposing factors remains controversial. In patients with PCM, the frequency of cancer is higher in smokers than in nonsmokers ${ }^{69}$. Diagnostic suspicion is fundamental for early diagnosis and treatment because clinical manifestations of cancer in patients with PCM can be masked by symptoms resulting from sequelae of fungal lesions in the lungs, larynx, or pharynx, especially in smokers and alcoholics. Less frequently, PCM manifests simultaneously or reoccurs with neoplasias, such as lymphoma, leukemia, and pulmonary carcinoma ${ }^{19,70}$. This PCM is probably opportunistic and presents with localized lesions, particularly in the lung or disseminated. 
These patients are generally treated with antifungal therapy and any deaths are attributed to neoplasia. In areas endemic to PCM, this mycosis should be considered in cases of cancer patients experiencing clinical worsening.

\section{Organ transplantation and immunosuppressive therapy}

Opportunistic PCM has been observed in patients with reduced cellular immunity as a result of renal or hepatic transplantation, use of immunosuppressants, such as corticosteroids and cytotoxic and immunobiological drugs for the treatment of several diseases, or, in rare cases, primary immunodeficiency. This is exemplified by a case report of rheumatoid arthritis and bone sarcoma in which the patient was medicated with adalimumab, methotrexate, and leflunomide, and presented with lung and bone disease related to Paracoccidioides spp. infection ${ }^{20}$. In a small number of cases, PCM manifested a few days to 14 years after kidney transplantation, which enabled the evaluation of PCM's clinical and laboratory characteristics under these conditions. Chest $\mathrm{X}$-rays revealed that these patients had bilateral nodules ${ }^{18}$, pulmonary cavitation ${ }^{71,72}$, or bronchopneumonic infiltrate ${ }^{73}$. Lymphatic impairment was uncommon $^{74}$. In these cases, microbiological diagnosis should be preferential because serological tests generally show low titers of anti-Paracoccidioides spp. antibodies ${ }^{73,75}$. As in other immunosuppressed patients, unusual clinical and serological expressions may confuse and delay the diagnosis of PCM. In addition, the response to therapy in renal transplant patients may be slow, especially with the administration of oral antifungal agents $^{72-74}$. In half of these cases, death was reported. The use of effective and intravenous antifungal agents is thus recommended, as well as rigorous monitoring of immunosuppressed patients who have been exposed to areas endemic to PCM.

\section{HIV infection and AIDS}

Opportunistic PCM has been observed in HIV-infected patients, with up to $1.5 \%$ of Brazilian AIDS cases reporting simultaneously PCM infection ${ }^{17,76}$. In these co-infected patients, PCM progresses more rapidly and lesions are more widespread, involving lymphadenomegaly, umbilicated cutaneous lesions, hepatosplenomegaly, pulmonary infiltrates, and lesions of the central nervous system and other tissues. Most cases present mixed clinical manifestations with lesions predominantly of acute/subacute PCM, but with frequent pulmonary lesions, which may be atypical ${ }^{43}$. Many patients have a low CD4 + lymphocyte count and may present PCM as the first manifestation of AIDS. Although about $30 \%$ of the cases do not present antiParacoccidioides spp. antibodies, the fungus is easily recognized or isolated in mycological or histopathological examinations. HIV/Paracoccidioides spp. co-infection can lead to death, but most patients can be cured with intensive antifungal treatment combined with antiretrovirals and secondary prophylaxis ${ }^{17}$.

\section{Recommendations for patients suspected of comorbidities and immunosuppression}

1. Request an acid-fast bacilli smear and culture in three samples of sputum from patients with pulmonary PCM, particularly those patients who present with fever, night sweats, and infiltrate and/or cavitation in the upper lobes of the lungs.

2. Perform an otorhinolaryngological follow-up in patients with laryngeal lesions that persist with dysphonia to perform a differential diagnosis with tuberculosis or neoplasia.

3. In patients with pulmonary involvement and declining respiratory function despite appropriate treatment, the following conditions should be considered: bacterial infection, smoking-related lung disease (COPD), or associated neoplasia or sequelae with functional consequences.

4. Investigate a possible HIV infection in patients with suggestive epidemiology and in patients with acute/ subacute or mixed form PCM.

5. In immunocompromised patients, the absence of antibodies, even in disseminated disease, does not rule out the diagnosis of PCM, which should be investigated with microbiological testing, and, if possible, with tissue biopsy and histopathological examination.

\section{SEQUELAE}

PCM is a systemic disease whose host response to the infecting agent consists of chronic granulomatous inflammation associated with an overlying fibrosing process. Thus, in addition to granuloma formation, there is an increased production of cytokines, including TNF- $\alpha$ and TGF- $\beta$, which can induce collagen and reticulin accumulation in the infected tissue. This fibrosing response may then lead to anatomical and functional changes in the organs affected during infection, especially the lungs.

\section{Pulmonary}

Despite treatment, chronic PCM may continue to present symptoms, such as varying degrees of cough, hyaline expectoration, and dyspnea ${ }^{41,42}$. In addition, changes in spirometry, including an obstructive pattern, may also be observed in most cases, which is justified by the association of peribronchial fibrotic sequelae with the history of smoking in most patients ${ }^{42}$. A complete lung function test may also show air trapping and diffusion reduction, which in more severe cases can lead to chronic hypoxemia ${ }^{42}$. Most patients, even after completing treatment, show scarring alterations upon imaging tests, especially CT scans ${ }^{44}$ (Figure 10), which can reveal architectural distortion $(90 \%)$, septal and reticulated thickening (88\%), centrolobular or parasseptal emphysema (82\%), bronchial thickening (82\%), parenchymal bands (74\%), scarring in emphysema areas (66\%), nodules $<3 \mathrm{~cm}(62 \%)$, and pulmonary cysts $(10 \%)^{42}$. In gasometry, an increased alveolararterial $\mathrm{O}_{2}$ gradient, hypoxemia, and hypercapnia may be present, with the latter signaling greater severity. Pulmonary hypertension is rare, and secondary to parenchymal changes.

\section{Adrenal glands}

On average, adrenal impairment is observed in $56 \%$ of autopsied cases, ranging from $48.2 \%$ to $80.0 \%{ }^{34,36}$. However, $15 \%$ to $50 \%$ of patients undergoing adrenal evaluation present with a hampered reserve, despite the absence of 
clinical manifestations, and $3.5 \%$ of these patients present with Addison's disease, which requires frequent hormonal replacement therapy throughout one's life ${ }^{49,50}$.

\section{Larynx}

Laryngeal sequelae are characterized by dysphonia, as hoarseness and alterations in airflow and indicate poor closure of the fibrotic vocal cords. These complications are associated with an increased risk of pulmonary infections by aspiration and even difficulty of socializing because the voice is so altered ${ }^{77}$. Sequelae of the trachea can lead to obstruction of the airway and subsequent respiratory insufficiencies that can require tracheostomy or even surgical correction of tracheal stenosis.

\section{Central nervous system}

Patients frequently develop motor deficits, convulsive syndromes (epilepsy), and/or hydrocephalus. Cerebellar impairment occurs in about $20 \%$ to $30 \%$ of PCM cases with neurological involvement, and these cases often rapidly evolve to intracranial hypertension, which requires ventricular shunting ${ }^{51,52}$. Neurological forms of PCM have substantial risks for sequelae.

\section{Skin}

Cutaneous sequelae can lead to esthetic and oral mucosa alterations and even microstomia, which require special care for patient feeding and surgical correction after antifungal treatment.

\section{Lymphatic}

The sequelae of the abdominal lymphatic system can lead to obstructive jaundice, as a result of lymph node involvement in the hepatic hilum ${ }^{78}$ and malabsorption syndrome of proteins and fats $^{54,79}$. The social and economical cost of these complications has not been adequately evaluated by the scientific community or health authorities.

\section{Evaluation and follow-up of pulmonary sequelae}

Patients with PCM that involves the lungs may present with persistent respiratory symptoms despite undergoing adequate treatment. Thus, the presence of respiratory sequelae in the lung that are associated with the pathologies or recurrence of PCM should be actively investigated in symptomatic patients ${ }^{80}$. Spirometry should be performed and, in the presence of an obstructive disorder, the introduction of bronchodilator medication is suggested, following guidelines for the treatment of COPD ${ }^{81}$. Chest X-rays and CTs not only aid in the investigation of associated pathologies, such as lung neoplasia, but also aid in the diagnosis of disease recurrence (onset or recrudescence of lesions with radiological signs of activity, such as nodules and masses with cavities and ground glass density nodules). Coinfections, especially tuberculosis (Table 2 and Table 4), should be investigated through microbiological examinations of sputum and, if necessary, bronchoalveolar lavage. Arterial blood gas

TABLE 4

Diagnostic approach to respiratory complaints in treated patients.

\begin{tabular}{|c|c|c|c|c|}
\hline Main differential diagnoses & Sputum microbiology & Sputum cytology & Chest X-ray and tomography & Serum (antibody/antigen) \\
\hline relapse & & & + For PCM* & \\
\hline
\end{tabular}

Infectious diseases

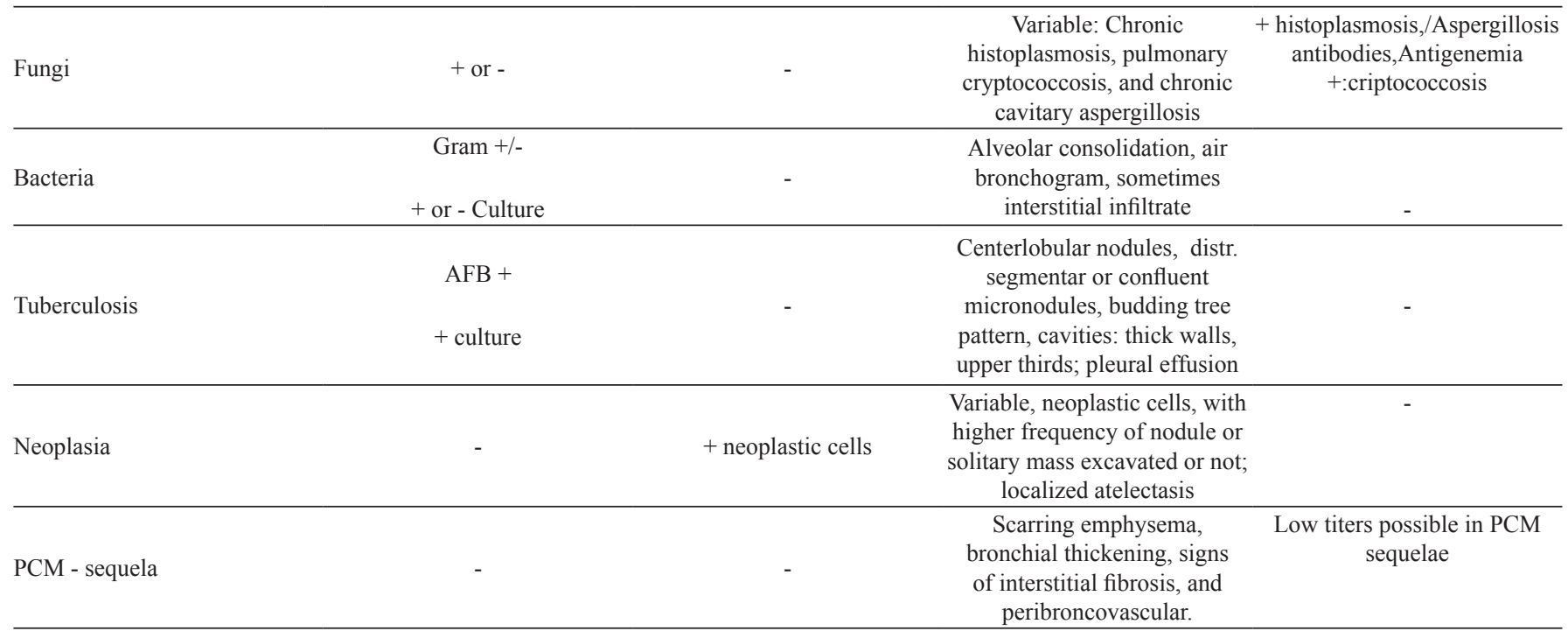

PCM: paracoccidioidomycosis;: AFB: acid-fast bacilli; +: positive ; -: negative ; \pm : positive or negative. *Consolidation, frosted glass lesions, thick-walled cavities, thickening of alveolar septa, nodules, and confluent masses. 
analysis may indicate the need for supplemental oxygen in cases of severe hypoxemia $\left(\mathrm{PaO}_{2}<55 \mathrm{mmHg}\right)$, and should be requested in patients with hypoxemia measured via pulse oximetry ${ }^{81}$. In more advanced cases from a clinical, spirometric, or laboratory point of view, a pulmonologist should perform an evaluation to characterize the severity and orientation of the therapy.

\section{TREATMENT}

Unlike other pathogenic fungi, $P$. brasiliensis and $P$. lutzii are susceptible to most systemic antifungal agents - even sulfonamide derivatives can inhibit their growth. There is no solid evidence to support primary or secondary resistance to the drugs used in PCM treatment. Therefore, several antifungal drugs have been shown to be effective in treating different clinical forms of the disease, including azole derivatives (ketoconazole, fluconazole, itraconazole, voriconazole, posaconazole, and isavuconazole ${ }^{82-87}$ ), sulfonamide derivatives (cotrimoxazole, sulfadiazine, etc. ${ }^{88}$, amphotericin B (formulations in deoxycholate, lipid and liposomal complex) for severe forms ${ }^{89-91}$, and even terbinafine ${ }^{92}$.

Despite the vast therapeutic arsenal available for disease management, itraconazole, cotrimoxazole (sulfamethoxazole/ trimethoprim combination), and amphotericin B are more commonly used in clinical practice. There is currently no in vitro or in vivo evidence showing that PCM by P. brasiliensis and $P$. lutzii respond differently to the antifungal agents used in the treatment of the disease. Therefore, the therapeutic recommendations are valid for all patients with PCM.

Although Latin America has high PCM incidence, morbidity, and mortality rates, only two randomized clinical trials involving patients with PCM have been published. However, neither study had statistical power capable of identifying crucial definitions, such as efficacy, safety, and treatment duration ${ }^{83,86}$. Thus, the suggested guidelines for PCM treatment are based on only two prospective, open randomized studies, and multiple retrospective or prospective, comparative or non-comparative studies ${ }^{82,86,90,93,94}$. Although tested in a small number of patients, voriconazole, posaconazole, and isavuconazole have been shown to have inhibitory action in vitro against Paracoccidioides spp. isolates, and therefore, these agents are potentially useful in the treatment of PCM. However, drug interactions and adverse events of prolonged therapy should be taken into account.

\section{Treatment of patients with mild and moderate forms}

Itraconazole at a dose of $200 \mathrm{mg}$ daily has been widely used in the treatment of mild and moderate forms of PCM with high rates of efficacy and safety. Therefore, at present, this triazole is the treatment of choice for patients with mild to moderate forms of PCM. The duration of treatment may vary from 9 to 18 months, with an average duraction of 12 months, and the patient should always be evaluated by clinical, immunological, and radiological criteria. (Table 5). In general, the tegumentary lesions heal 30 days after the start of treatment and the lymphadenopathies regress between 45 and 90 days. Stabilization of radiological images is usually observed after 6 months of itraconazole use.

As with many triazole fungicides, the absorption of itraconazole may be impaired by a number of factors, such as drug interactions, achlorhydria, previous gastrectomy, alkaline food intake, or fasted state (Table 5, Table 6, Table 7, and Table 8). For increased serum levels in adult patients, itraconazole capsules should be ingested in a single intake after lunch or dinner. Acidic beverages, such as citrus juices, can increase the absorption of itraconazole, while alkaline foods decrease absorption. Fractionated dosing of itraconazole is not recommended because its absorption from the gastrointestinal tract occurs only when the drug is packed in intact capsules. In terms of clinical efficacy (predominantly with chronic PCM), treatment duration and adherence, and pharmacoeconomics, several retrospective, comparative studies have shown that the treatment of PCM with itraconazole is more advantageous than treatment with sulfamethoxazole/ trimethoprim (cotrimoxazole) $)^{93,94}$.

TABLE 5

Most commonly used drugs in patients with paracoccidioidomycosis.

\begin{tabular}{|c|c|c|}
\hline Drugs & Dose & Average duration \\
\hline Itraconazole* & $\begin{array}{c}200 \mathrm{mg} \text { daily } \\
* * \text { Children }<30 \mathrm{~kg} \mathrm{e}>5 \text { years, } 5 \text { to } 10 \mathrm{mg} / \mathrm{kg} / \text { day, adjust dose without } \\
\text { opening the capsule }\end{array}$ & 9-18 months \\
\hline Cotrimoxazole* & $\begin{array}{l}\text { Trimethoprim, } 160 \mathrm{mg}+\text { Sulfamethoxazole, } 800 \mathrm{mg}(\mathrm{VO} 8 / 8 \mathrm{~h} \text { or } 12 / 12 \mathrm{~h}) \\
\text { Children -Trimetoprim, } 8 \text { to } 10 \mathrm{mg} / \mathrm{kg}+\text { Sulfamethoxazole, } 40 \text { to } \\
50 \mathrm{mg} / \mathrm{kg}, \mathrm{VO} 12 / 12 \mathrm{~h}\end{array}$ & 18-24 months*** \\
\hline Amphotericin B & $\begin{array}{l}\text { Deoxycholate } 0.5-0.7 \mathrm{mg} / \mathrm{kg} / \text { day (IV) } \\
\text { Lipid formulation } 3-5 \mathrm{mg} / \mathrm{kg} / \text { day (IV) }\end{array}$ & 2-4 weeks**** (until improvement) \\
\hline
\end{tabular}

CNS: central nervous system. *Do not use concomitantly with astemizole, antacids and H2 blockers, barbiturates, cisapride, cyclosporine, didanosine, digoxin, fentanyl, phenytoin, rifampicin, cisapride, and terfenadine. $* *$ Increased experience in children with sulfamethoxazole/trimethoprim treatment. $* * *$ Extend the duration of treatment when there is CNS involvement. $* * * *$ Requires maintenance treatment with itraconazole or cotrimoxazole. 
TABLE 6

Drug interactions of sulfamethoxazole + trimethoprim and amphotericin B.

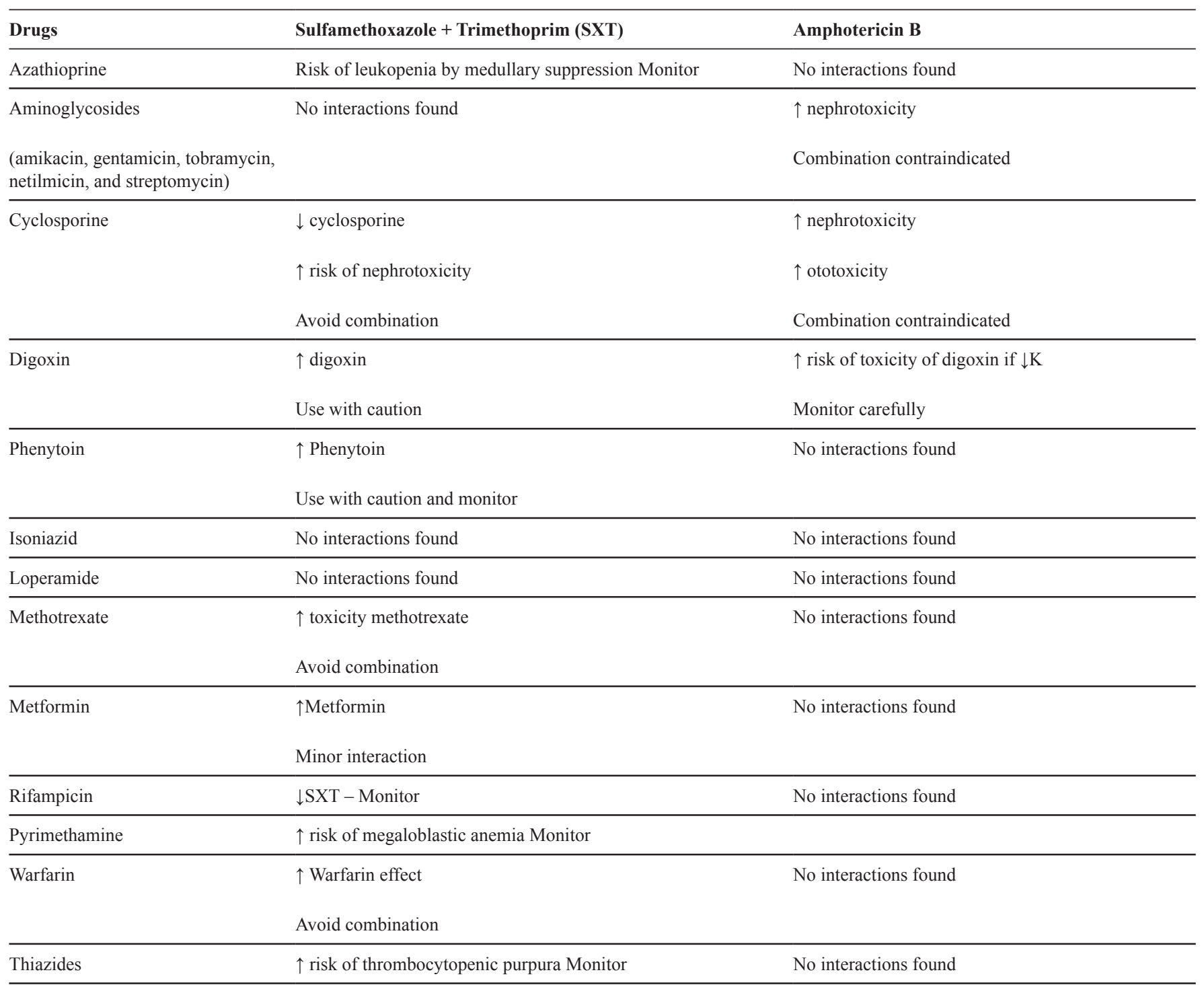

K: potassium; SXT: sulfametoxazole-thrimethoprim; References: http://reference.medscape.com/drug-interactioncheck ${ }^{95}$; https://online.epocrates.com/interactioncheck $^{96}$.

\section{New azole derivatives}

Although only a small number of patients have been treated with other drugs on the expanded triazole spectrum triazoles, including voriconazole, posaconazole (with expected future use with extended release capsules), and isavuconazol, these drugs can be considered as potential substitutes for itraconazole as their costs become more affordable and new evidence is published $^{86,87}$; however, drug interactions should be taken into account ${ }^{95,96}$ (Table 6, Table 7 and Table 8).

\section{Cotrimoxazole (sulfamethoxazole/trimethoprim)}

Although cotrimoxazole is fungistatic and requires a longer treatment duration than that of itraconazole, cotrimoxazole is the second treatment option for patients with mild to moderate forms of PCM. Cotrimoxazole's advantages include large availability within Brazil's public health system, tablet form, oral and venous formulations, and good absorption with predictable serum levels. The oral suspension can be used in children who do not tolerate tablets and in adults who do not swallow tablets because of stenotic laryngeal or esophagus lesions. The cotrimoxazole venous solution can be used in patients with digestive disorders and/or who do not absorb oral medication well. Cotrimoxazole can also be used in contraindications of itraconazole, or in cases of suspected therapeutic failure or concomitant tuberculosis treatment. According to a few published cases, cotrimoxazole is the treatment of choice for patients with neuroparacoccidioidomycosis ${ }^{52,97}$. 
TABLE 7

Main drug interactions for azole antifungals.

\begin{tabular}{|c|c|c|c|c|c|}
\hline Drugs & Fluconazole & Itraconazole & Ketoconazole & Voriconazole & Posaconazole \\
\hline Amitriptyline & $\begin{array}{l}\uparrow \mathrm{QT} * \text { *Avoid } \\
\text { combination }\end{array}$ & $\begin{array}{l}\uparrow \mathrm{QT}^{*} \text { Avoid } \\
\text { combination }\end{array}$ & $\begin{array}{l}\uparrow \mathrm{QT}^{*} \text { Avoid } \\
\text { combination }\end{array}$ & $\begin{array}{l}\uparrow \mathrm{QT}^{*} \text { Avoid } \\
\text { combination }\end{array}$ & $\begin{array}{l}\uparrow \mathrm{QT}^{*} \text { Avoid } \\
\text { combination }\end{array}$ \\
\hline Warfarin & $\begin{array}{l}\text { } \uparrow \text { Warfarin } \\
\text { Avoid } \\
\text { combination } \\
\end{array}$ & $\begin{array}{l}\uparrow \text { Warfarin } \\
\text { Avoid combination }\end{array}$ & $\begin{array}{l}\uparrow \text { Warfarin } \\
\text { Avoid combination }\end{array}$ & $\begin{array}{l}\uparrow \text { Warfarin } \\
\text { Avoid combination }\end{array}$ & $\begin{array}{l}\uparrow \text { Warfarin } \\
\text { Avoid combination }\end{array}$ \\
\hline $\begin{array}{l}\text { Calcium channel } \\
\text { blockers }\end{array}$ & $\begin{array}{l}\uparrow \text { blocker effect } \\
\text { Combination not } \\
\text { contraindicated } \\
\end{array}$ & $\begin{array}{l}\uparrow \text { blocker effect } \\
\text { Combination not } \\
\text { contraindicated } \\
\end{array}$ & $\begin{array}{l}\uparrow \text { blocker effect } \\
\text { Combination not } \\
\text { contraindicated } \\
\end{array}$ & $\begin{array}{l}\uparrow \text { blocker effect } \\
\text { Combination not } \\
\text { contraindicated } \\
\end{array}$ & $\begin{array}{l}\uparrow \text { blocker effect } \\
\text { Combination not } \\
\text { contraindicated } \\
\end{array}$ \\
\hline $\begin{array}{l}\text { H2 blockers, antacids, } \\
\text { sucralfate }\end{array}$ & No interactions found & $\begin{array}{l}\downarrow \text { Itraconazole } \\
\text { Avoid combination }\end{array}$ & $\begin{array}{l}\downarrow \text { Ketoconazole } \\
\text { Avoid combination }\end{array}$ & No interactions found & $\begin{array}{l}\downarrow \text { Posaconazole } \\
\text { Avoid combination }\end{array}$ \\
\hline Carbamazepine & $\begin{array}{l}\uparrow \text { Carbamazepine } \\
\text { Monitor serum } \\
\text { carbamazepine level } \\
\text { Use with caution }\end{array}$ & $\begin{array}{l}\uparrow \text { Carbamazepine } \\
\downarrow \text { Itraconazole } \\
\text { Monitor serum } \\
\text { carbamazepine level } \\
\\
\text { Use with caution }\end{array}$ & $\begin{array}{l}\uparrow \text { Carbamazepine } \\
\downarrow \text { Ketoconazole } \\
\text { Monitor serum } \\
\text { carbamazepine level } \\
\\
\text { Use with caution }\end{array}$ & $\begin{array}{l}\uparrow \text { Carbamazepine } \\
\downarrow \text { Voriconazole } \\
\text { Combination } \\
\text { contraindicated }\end{array}$ & $\begin{array}{l}\uparrow \text { Carbamazepine } \\
\downarrow \text { Posaconazole } \\
\text { Monitor serum } \\
\text { carbamazepine level } \\
\\
\text { Use with caution }\end{array}$ \\
\hline Phenytoin & $\begin{array}{l}\text { } \text { Phenytoin } \\
\text { Use with caution }\end{array}$ & $\begin{array}{l}\downarrow \text { Itraconazole } \\
\text { Avoid } \\
\text { combination }\end{array}$ & $\begin{array}{l}\uparrow \text { Phenytoin } \\
\downarrow \text { Ketoconazole } \\
\text { Avoid combination }\end{array}$ & $\begin{array}{l}\uparrow \text { Phenytoin } \\
\downarrow \text { Voriconazole } \\
\text { Avoid combination } \\
\text { or monitor }\end{array}$ & $\begin{array}{l}\uparrow \text { Phenytoin } \\
\downarrow \text { Posaconazole } \\
\text { Avoid combination }\end{array}$ \\
\hline Isoniazid & No interactions found & $\begin{array}{l}\downarrow \text { Itraconazol e Monitor } \\
\text { serum level }\end{array}$ & $\begin{array}{l}\downarrow \text { Ketoconazole } \\
\text { Combination } \\
\text { contraindicated } \\
\end{array}$ & $\begin{array}{l}\uparrow \text { Voriconazole } \\
\text { Monitor serum level }\end{array}$ & $\begin{array}{l}\text { No interactions } \\
\text { found }\end{array}$ \\
\hline $\begin{array}{l}\text { Proton pump } \\
\text { inhibitors } \\
\text { (omeprazole) }\end{array}$ & $\begin{array}{l}\uparrow \text { effect of proton } \\
\text { pump inhibitors } \\
\text { Use with caution }\end{array}$ & $\begin{array}{l}\downarrow \text { Itraconazole } \\
\text { Avoid combination }\end{array}$ & $\begin{array}{l}\downarrow \text { Ketoconazole } \\
\text { Combination } \\
\text { contraindicated }\end{array}$ & $\begin{array}{l}\uparrow \text { effect of proton } \\
\text { pump inhibitors } \\
\text { Use with caution }\end{array}$ & $\begin{array}{l}\downarrow \text { Posaconazole } \\
\text { Avoid } \\
\text { combination }\end{array}$ \\
\hline $\begin{array}{l}\text { Midazolam/ } \\
\text { triazolam } \\
\text { oral }\end{array}$ & $\begin{array}{l}\uparrow \text { Midazolam } \\
\text { Risk of respiratory } \\
\text { depression Avoid } \\
\text { combination }\end{array}$ & $\begin{array}{l}\uparrow \text { Midazolam } \\
\text { Risk of respiratory } \\
\text { depression } \\
\text { Combination } \\
\text { contraindicated }\end{array}$ & $\begin{array}{l}\uparrow \text { Midazolam } \\
\text { Risk of respiratory } \\
\text { depression } \\
\text { Combination } \\
\text { contraindicated }\end{array}$ & $\begin{array}{l}\uparrow \text { Midazolam } \\
\text { Risk of respiratory } \\
\text { depression } \\
\text { Avoid combination }\end{array}$ & $\begin{array}{l}\uparrow \text { Midazolam } \\
\text { Risk of respiratory } \\
\text { depression } \\
\text { Avoid } \\
\text { combination }\end{array}$ \\
\hline $\begin{array}{l}\text { Rifampicin/ } \\
\text { rifabutin }\end{array}$ & $\begin{array}{l}\downarrow \text { Fluconazole } \\
\downarrow \text { Rifampicin } \\
\text { Consider increasing } \\
\text { the dose of } \\
\text { fluconazole }\end{array}$ & $\begin{array}{l}\downarrow \text { Itraconazole } \\
\downarrow \text { Rifampicin Monitor } \\
\text { treatment efficacy }\end{array}$ & $\begin{array}{l}\downarrow \text { Ketoconazole } \\
\downarrow \text { Rifampicin } \\
\text { Monitor treatment } \\
\text { efficacy }\end{array}$ & $\begin{array}{l}\downarrow \text { Voriconazole } \\
\downarrow \text { Rifampicin } \\
\text { Combination } \\
\text { contraindicated }\end{array}$ & $\begin{array}{l}\downarrow \text { Posaconazole } \\
\downarrow \text { Rifampicin } \\
\text { Monitor treatment } \\
\text { efficacy }\end{array}$ \\
\hline Sirolimus & $\begin{array}{l}\uparrow \text { Sirolimus } \\
\text { Combination } \\
\text { contraindicated } \\
\end{array}$ & $\begin{array}{l}\uparrow \text { Sirolimus } \\
\text { Use with caution }\end{array}$ & $\begin{array}{l}\uparrow \text { Sirolimus } \\
\text { Combination } \\
\text { contraindicated } \\
\end{array}$ & $\begin{array}{l}\uparrow \text { Sirolimus } \\
\text { Combination } \\
\text { contraindicated }\end{array}$ & $\begin{array}{l}\uparrow \text { Sirolimus } \\
\text { Combination } \\
\text { contraindicated } \\
\end{array}$ \\
\hline Tacrolimus & $\begin{array}{l}\uparrow \mathrm{QT} \\
\uparrow \text { Tacrolimus } \\
\text { Avoid combination } \\
\end{array}$ & $\begin{array}{l}\uparrow \text { Tacrolimus } \\
\text { Avoid combination }\end{array}$ & $\begin{array}{l}\uparrow \text { Tacrolimus } \\
\text { Avoid combination }\end{array}$ & $\begin{array}{l}\uparrow \text { Tacrolimus } \\
\text { Use with caution }\end{array}$ & $\begin{array}{l}\uparrow \text { Tacrolimus } \\
\text { Use with caution }\end{array}$ \\
\hline
\end{tabular}

References: $\mathrm{http}: / /$ reference.medscape.com/drug-interactioncheck ${ }^{95}$; https://online.epocrates.com/interaction-check ${ }^{95}$; ${ }^{\mathrm{QT}}$ interval in electrocardiogram. 
TABLE 8

Drug interaction between antiretrovirals and azole antifungals.

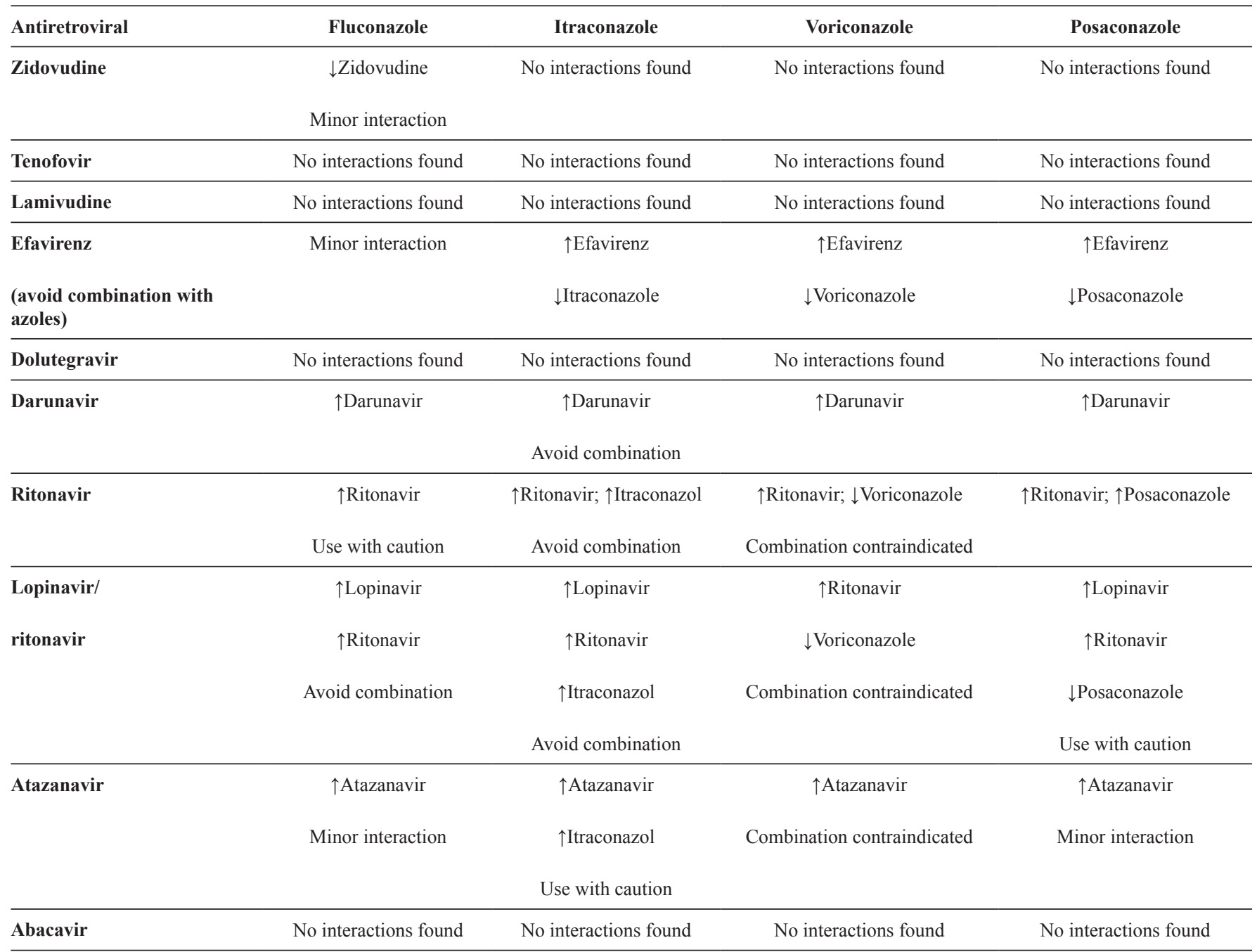

References: http://reference.medscape.com/drug-interactioncheck ${ }^{95}$; https://online.epocrates.com/interaction-check ${ }^{96}$.

\section{Treatment of patients with severe and disseminated forms}

For severe and disseminated forms of PCM, amphotericin $\mathrm{B}$ in deoxycholate or in lipid formulation (liposomal or lipid complex) is indicated for use. The recommended induction dose of conventional amphotericin B is $0.5-0.7 \mathrm{mg} / \mathrm{kg} /$ day, with a maximum of $50 \mathrm{mg} /$ day. Lipid formulations should be prescribed at doses of 3 to $5 \mathrm{mg} / \mathrm{kg} / \mathrm{day}$. The duration of treatment depends on the clinical stability of the patient and amphotericin B should be administered for the shortest possible time (on average 2 to 4 weeks). Transition to oral medication during the consolidation phase should occur after clinical stabilization once the drug's oral absorption has been confirmed.

If the lipid formulations of amphotericin B cannot be used, intravenous cotrimoxazole formulation is recommended at a dose of $800 \mathrm{mg} / 160 \mathrm{mg}$ every 8 hours. Despite having little clinical experience, intravenous fluconazole $(600$ to $800 \mathrm{mg} /$ day) can also be a therapeutic option.
The main therapeutic challenges of PCM management are the continuous use of systemic antifungal agents for extended periods, the possibility of relapse, and the appearance of sequelae, mainly in the respiratory tract. In addition to the use of antifungal drugs, PCM therapeutic management should include measures that improve the patient's general condition, treatment of infectious or non-infectious comorbidities, application of cure criteria, and post-therapeutic follow-up.

\section{Corticosteroids}

Although scarce, there is evidence in the literature that some patients with PCM may benefit from the use of corticosteroids concomitantly with antifungal treatment ${ }^{98}$. Patients that have been shown to benefit from this approach often have intense inflammation, either in the ganglia or central nervous system, serious lesions of the larynx or trachea, and lung lesions resulting in respiratory insufficiency. The use of prednisone for 1 to 2 weeks can reduce inflammation during therapy with antifungal 
agents. In patients with PCM and AIDS who are administered antifungal and antiretroviral drugs but still present with worsening clinical symptoms, the possibility of immune reconstitution inflammatory syndrome (IRIS) may be taken into account, based on other infections associated with HIV/AIDS.

\section{General measures}

All patients should be treated long enough to reduce signs and symptoms, stabilize body weight, have clear chest $\mathrm{X}$-rays, and appropriate serum antibody titers. In addition to specific antifungal therapy, patients with severe forms of PCM need general measures to improve their nutritional status and immunosuppression. Regulating smoking, alcohol consumption, adrenal insufficiency, and other associated conditions also contribute to a better patient outcome. Therefore, the following factors are important in achieving PCM cured criteria: rest, a hyperproteic and hypercaloric diet supplemented with vitamins, alcohol and tobacco restriction, and treatment of Addison's disease and associated infections, such as enteroparasitoses and respiratory bacterial co-infections. However, these recommended measures are useless if the patient cannot access antifungal medication, which the majority of the individuals with PCM cannot do because of their socioeconomic status and inability to afford treatment. Therefore, in the future, outpatient medications (itraconazole and cotrimoxazole) should be provided free of charge.

\section{Therapy in special populations}

\section{Pregnancy}

PCM can occur in pregnant women either as an initial manifestation or as a reactivation of a previously controlled fungal disease. PCM is believed to occur in pregnant women because of the reduction of immune responses in pregnancy, which also predisposes these women to other systemic mycoses. In one study, Paracoccidioides spp. disseminated to the placenta, but there were no reports of fetal involvement ${ }^{99}$. PCM in pregnant women is controllable with the usual antifungal agents, primarily amphotericin B (category B). However, with the possibility of a teratogenic effect, the use of azole drugs (category C) and sulfamethoxazole/trimethoprim (category D) should be avoided ${ }^{100}$. Amphotericin B (category B) and sulfadiazine (category C) are alternatives for use during all gestational periods, but sulfadiazine should be discontinued 15 days before the expected delivery date to avoid neonatal complications. Sulfamethoxazole/trimethoprim may be used during breastfeeding ${ }^{100}$. Antifungal therapy should be maintained throughout all gestational periods to prevent relapse and postpartum discontinuation should be assessed by the usual cure criteria. After birth, conventional antifungal therapy should be administered until the patient reaches the cure criteria.

\section{AIDS}

Patients with AIDS generally have severe and widespread forms of PCM; therefore, these patients should be initially treated with amphotericin B or, if appropriate, with high doses of itraconazole, $600 \mathrm{mg} /$ day (with attention towards interactions with antiretroviral drugs) or intravenous sulfamethoxazole/ trimethoprim ( 2 ampoules every 8 hours). Despite having limited clinical experience, intravenous fluconazole $(600-800 \mathrm{mg} /$ day $)$ may be a therapeutic option. To avoid possible drug interactions, PCM should be treated initially with antifungals for 3 to 5 weeks prior to initiation of antiretroviral therapy. Following the cure of PCM, secondary prophylaxis with sulfamethoxazole $(1,600 \mathrm{mg} /$ day $)$, trimethoprim $(320 \mathrm{mg} /$ day $)$, or itraconazole $(200 \mathrm{mg} /$ day) is recommended based on the treatment of other mycoses in immunocompromised patients. Prophylaxis should continue until the administered antiretroviral therapy elevates the CD4 lymphocyte count to a minimum of 100 cells/ $\mu \mathrm{L}$ (concomitantly with undetectable viral load) to 200 cells $/ \mu \mathrm{L}$, regardless of viral load for at least 3 months. The use of sulfamethoxazole/trimethoprim (800/160mg every 12 hours) is also effective as a primary and secondary prophylaxis for pneumocystosis and as primary prophylaxis for neurotoxoplasmosis. In immunosuppressed patients, the absence of antibodies, even in disseminated disease, does not rule out the diagnosis of PCM, which should be investigated with microbiological tests and, if possible, with tissue biopsy and histopathological examination.

\section{Hepatic or renal insufficiency}

The doses of the drugs used in PCM treatment should be adjusted in patients with hepatic or renal impairment.

\section{Renal insufficiency ${ }^{101-103}$}

\section{Amphotericin B}

This drug should be avoided because of its high potential for nephrotoxicity, which is compounded with the use of consecutive series. Serum amphotericin B levels are not significantly affected by hemodialysis and do not require adjustment in these cases. One should opt for other drugs or a lipid formulation of amphotericin B.

\section{Azoles}

Since several azoles present renal excretion, their dose should be adjusted as follows ${ }^{101-103}$.

Fluconazole: this azole has $80 \%$ renal clearance, and when renal clearance is less than $50 \mathrm{ml} / \mathrm{min}$, the dose should be reduced to $50 \%$ and administered at intervals of 48 hours. If renal clearance is less than $20 \mathrm{ml} / \mathrm{min}$, the dose should be reduced to one-third of the normal dose and administered at intervals of 72 hours. In the case of hemodialysis, the full dose should be used after the dialysis process and $50 \%$ of the normal dose should be used during peritoneal dialysis.

Itraconazole: when renal clearance is less than $10 \mathrm{ml} / \mathrm{min}$, the dose should be reduced to $50 \%$. In the case of hemodialysis or peritoneal dialysis, $100 \mathrm{mg}$ of an oral solution should be administered every 12 to 24 hours.

Voriconazole: when creatinine clearance is more than $50 \mathrm{ml} /$ $\mathrm{min}$, use a $6 \mathrm{mg} / \mathrm{kg}$ loading dose every 12 hours twice, followed by a $4 \mathrm{mg} / \mathrm{kg} /$ day every 12 hours. Do not use an IV solution when clearance is less than $50 \mathrm{ml} / \mathrm{min}$. In cases of renal replacement therapy, hemodialysis, or peritoneal dialysis use $4 \mathrm{mg} / \mathrm{kg} /$ day every 12 hours. 
Terbinafine: when clearance is greater than $50 \mathrm{ml} / \mathrm{min}$, administer a dose only every 24 hours, and avoid use when clearance is less than $50 \mathrm{ml} / \mathrm{min}$.

\section{Sulphamidic derivatives}

Sulphamidic derivatives present renal excretion and their metabolites may cause toxicity because they are poorly soluble at an acidic $\mathrm{pH}$ (urine), resulting in the formation of crystals that are deposited in the renal tubules that can lead to obstruction and subsequent kidney damage. Cases of interstitial nephritis have also been reported. These derivatives can be removed by dialysis. As a result, these products should be avoided in patients with renal insufficiency.

\section{Functional liver changes ${ }^{101-104}$}

PCM can cause functional liver changes via hepatocytic injury or extrinsic cholestatic compression ${ }^{104}$. In these cases, PCM treatment follows the proposed standards and the patient typically exhibits satisfactory responses. However, hepatotoxicity induced by antifungal agents may occur.

\section{Amphotericin B}

This drug has been known to accumulate in organs, often remaining in the liver, but rarely leading to an increase in transaminases. Amphotericin B deoxycholate is slightly hepatotoxic, unlike its lipid derivatives, which have the disadvantage of displaying a higher hepatic toxicity. Liver failure does not cause significant retention of the drug, which maintains a stable serum level.

\section{Azoles}

The biochemical changes observed with itraconazole persist with continued treatment. In treatment with cotrimoxazole and itraconazole, the commonly reported biochemical changes do not exceed $5 \mathrm{x}$ the upper limit of normality, which allows the maintenance of the treatment. However, there are case reports in which itraconazole had to be discontinued. Of the azoles, fluconazole is the least hepatotoxic.

\section{Metabolized in the liver with contraindications relating to serious liver diseases}

Ketoconazole, voriconazole and Sulphonamides

Voriconazole and ketoconazole are the most hepatotoxic agents, followed by itraconazole ${ }^{105}$. Therefore, these agents should be avoided in cases of severe hepatic impairment. Fluconazole can be used with great caution if the patient cannot be treated with amphotericin.

\section{Metabolized in the liver with adjusted doses relating to liver diseases}

Voriconazole should be administered at $6 \mathrm{mg} / \mathrm{kg}$ every 12 hours for two doses, followed by a dose of $2 \mathrm{mg} / \mathrm{kg}$ /day every 12 hours.

\section{Sulphamidic derivatives}

These agents rarely cause severe hepatotoxic injury, and may be used. Despite treatment maintenance, liver toxicity induced by cotrimoxazole evolves with the normalization of serum liver enzymes. In patients with hepatic impairment caused by other conditions, such as cirrhosis or alcoholic liver disease, amphotericin B deoxycholate should be used because it is less toxic to the liver than other preparations. An alternative agent is fluconazole.

\section{Paracoccidioidomycosis in children ${ }^{39,40,106,107}$}

In children infected with PCM, the most commonly used treatment is the combination of sulfamethoxazole/trimethoprim because it has known efficacy, good tolerability, syrup-like presentation for dose administration and adequacy, and is provided by the public health network ${ }^{39,40,106}$. The recommended dose ranges between 8 to $10 \mathrm{mg} / \mathrm{kg} /$ day of trimethoprim in two daily doses, and no fasting is required. Intravenous formulation is an alternative when the oral route is contraindicated, as in cases of intestinal subocclusion. The intravenous formulation should be administered at the same dosage twice a day. Among the side effects reported, leukopenia is frequent; however, this condition can be controlled without other associated complications with the concomitant use of folinic acid ${ }^{106}$.

Itraconazole may be used as a second option at a dose of 5 to $10 \mathrm{mg} / \mathrm{kg} /$ day once daily. Amphotericin B deoxycholate, as well as other formulations of amphotericin B, is reserved for severe cases ${ }^{108}$. During treatment, some patients may present with a paradoxical reaction characterized by clinical worsening, such as new lymph node enlargements, fistulization, fever, and weight loss. In this case, steroids should be administered ${ }^{108}$.

\section{Paracoccidioidomycosis in situations of limited resources}

In Rondônia, a systematic registry of PCM cases has been maintained since 1997, with periods of more than 15 cases per 100,000 inhabitants occurring over the years. In the stratified analysis by municipality, periods of almost 40 cases per 100,000 inhabitants were documented in the southern region of the state $^{14}$.

Individuals with PCM who are rural workers with low levels of education, precarious socioeconomic statuses, and difficulty assessing health care services are susceptible to delayed diagnoses, which may contribute to the disease's aggravation with evolution to sequelae. In Rondônia, about one-third of the patients with PCM had a diagnosis based on clinicalepidemiological criteria ${ }^{14}$, as serological examination was not an available method during this period. In the last 4 years, data on more than 100 PCM cases treated at the Tropical Medicine Center of Rondônia showed a predominance of the chronic form with frequent mucosal involvement. Further, treatment usually began approximately 7 months after infection and persisted until a therapeutic response from both cotrimoxazole and itraconazole was observed. The expansion of the diagnostic network; the standardization and availability of antigens of the different species described to perform serological tests; the training of health professionals, often from other states and still not aware of the regional importance of PCM; and the availability of easyto-administer medicines by the public authorities, can contribute to a better approach to the disease. 


\section{Criteria for cure}

After the diagnosis of PCM has been confirmed, treatment involves long-term regimens with periodic follow-up, usually on an outpatient basis. The duration of therapy should be evaluated according to the cure criteria based on clinical, mycological, radiological, and immunological parameters.

\section{Clinical criteria}

Cure clinical criteria for PCM include the absence or regression of disease signs and symptoms of the disease, such as the healing of tegumentary lesions, involution of adenomegaly, and stabilization of body weight. The patient's oral lesions subjectively improve after 2 weeks of initial treatment, and after 1 month, there is lesion scarring. In addition, skin lesions also regress after 1 month and lymphadenomegaly occurs between 2 and 3 months. It is common to observe the persistence of residual symptoms or sequelae as a result of lesion scarring and fibrosis. The most commonly observed sequelae occur in the lungs, lymphatic system, adrenals, and CNS. Signs and symptoms resulting from sequelae should be differentiated from the clinical presentation of active disease.

\section{Mycological criteria}

Negative direct mycological examination in clinical specimens occurs early if treatment is effective. This parameter is more easily verified when examining respiratory secretions. In other materials, such as biopsies or lymph node secretions, fungal assessment is unnecessary because the lesions regress or disappear with treatment.

\section{Radiological criteria}

Pulmonary opacities, initially of nodular, micronodular, or reticular pattern, and cavitary lesions tend to become linear images, indicating pulmonary lesion scarring and fibrosis. The stabilization of pulmonary radiological image patterns should be analyzed in semiannual chest X-rays (Table 3).

\section{Immunological criteria}

The most commonly used serological method for detecting antibodies is the DID reaction. An antibody titer is expected to be negative or stabilized at low levels with treatment (undiluted serum or 1:2 dilution). Alternatively, when using counterimmunoelectrophoresis (CIE), stabilization occurs in undiluted serum until a 1:4 dilution. Serological evaluations should be conducted every 6 months, when available.

\section{Post-treatment follow-up}

The term definitive cure can never be applied to patients with PCM because P. brasiliensis cannot be eradicated from the organism. Therefore, the aim PCM treatment is to reduce the fungal load in the patient's body, allowing cellular immunity and the balance between parasite and host to recover. After treatment and the observation of cure criteria, patients should undergo outpatient follow-up with routine clinical and serological evaluation. Clinical relapse can be indicated by a positive titer or increase in the DID titer value. Periodic clinical examination with weight control and verification of oral lesion or lymphadenopathy occurrence should be performed for a period of up to 1 year after achieving the cure criteria.

\section{CONTROL, PREVENTION, CHALLENGES, AND RECOMMENDATIONS}

\section{Control and prevention}

Currently, a vaccine to prevent Paracoccidioides spp. infection in humans is not available, although promising results have been observed in laboratory animals ${ }^{109}$. Recommendations for the prevention of PCM derive from knowledge of the most obvious infection situations, which occur as a result of aerial exposure to conidia in endemic areas and predisposing risk factors.

In both rural and periurban environments, inhabitants should avoid exposure to dust from soil excavation, earthworks, and plant manipulation. For rural workers and tractor drivers who are constantly exposed to the dense dust, such as those who perform hand-picking, cleaning (sweeping), and coffee sweeping, exposure should be avoided by using well-sealed cabin machines or N95 respirators (not always available). In practice, the replacement of manual coffee sweeping with an oven may have contributed to an observed decrease in PCM incidence among the former coffee regions. Further, children and immunosuppressed individuals are advised to avoid to situations of risk in rural areas. In laboratories, the manipulation of fungal isolates should be performed in a safety hood, especially if the cultures are in the mycelium form. For laboratories that routinely handle Paracoccidioides spp., pre-exposure and annual serological examination of researchers is recommended to monitor possible fungal infection. Accidents in a research laboratory involving transdermal inoculation of Paracoccidioides spp. should be managed by monitoring the presence of antifungal antibodies in the affected person at the time of suspected infection, after 3 months, and after 6 months. Prophylaxis with itraconazole should be administered orally at $200 \mathrm{mg} /$ day for 30 days.

Since chronic PCM has been shown to be associated with both smoking and average alcohol consumption ${ }^{16}$, smoking and excessive alcohol consumption (and subsequent malnutrition) should be avoided before and after exposure. Patients immunosuppressed by drugs and/or transplants ${ }^{20,110}$ have an increased risk of developing PCM. Since a case report has described the transmission of supra-renal PCM through kidney donation ${ }^{111}$, prior evaluation of organs from donors suspected of having epidemiological antecedents is recommended. Respective donor recipients suspected of having epidemiological antecedents should also be evaluated before and during immunosuppression via a chest radiograph and Paracoccidioides spp. antibody test.

\section{Challenges}

In addition to improving the prevalence and incidence rates of PCM, there are a number of new challenges in the management of the disease, such as the registration of cases by compulsory notification and notification through drug access in outpatient and inpatient cases, standardization of serological methods, critical evaluation of antifungal therapies and corticosteroid use, search for new therapeutic approaches for sequelae, the $P$. brasiliensis complex, and the description of a new species of Paracoccidioides, P. lutzii. 
For the clinician, it is important to evaluate the current epidemiological, clinical, diagnostic, and therapeutic impact of the different species on the human disease. For instance, the north and midwest regions have been associated with PCM infections caused by P. lutzii because of molecular identification of isolates in these areas ${ }^{1,5,9}$ and higher sera reactivity of patients with proven disease in these areas to $P$. lutzii antigen ${ }^{63,64}$.

Although clinical data and therapeutic response are similar for both species (data from Mato Grosso do Sul), little is known about the isolation and molecular identification of the species in patients ${ }^{8}$ because mycological and histopathological examinations cannot distinguish these species and molecular tests are not available in routine laboratories ${ }^{66}$.

The following issues remain unanswered: knowledge of the epidemiological-molecular profile of Paracoccidioides isolates in Brazil to enhance the clinical-epidemiological diagnosis; characterization of the antigenic profile of the isolates and their correlation with clinical-laboratory data of disease caused by both species ${ }^{1,7}$, including sequelae and response to different drugs, as well as analysis of drug susceptibility ${ }^{112,113}$.

Of great importance to public health is the introduction of simple methods, such as mycological examination, that can serve as the first choice in diagnosis in poor regions. These methods would be especially useful in cases where tuberculosis diagnosis is excluded. However, this requires the joint effort of public agencies and the academic community to develop a serological diagnosis that is universally available for both $P$. lutzii and $P$. brasiliensis infections, with stable antigenic fractions and easily reproducible tests. The international academic community has united the endemic Latin American countries to create the Latin American Network of Paracoccidioidomycosis through the Working Group on Paracoccidioidomycosis ${ }^{14}$ to overcome these challenges. The dissemination of knowledge collected from clinical-epidemiological, mycological, and serological data in all endemic regions is also a fundamental step for the early diagnosis, treatment, and establishment of comprehensive patient care.

\section{Recommendations}

The following are general recommendations for improving the care of patients with PCM:

1. Institute a compulsory notification of cases with probable and proven PCM;

2. Create a national registry of cases through notification via access to medicine or hospitalization;

3. Enable universal access to itraconazole and cotrimoxazole for treatment of mild to moderate forms;

4. Enable access to lipid formulations of amphotericin in special situations, such as immunosuppression, and to amphotericin B deoxycholate, which has been released for marketing after receiving approval of minimum pharmacological requirements;

5. Structure a basic care network based on clinicalepidemiological, mycological (direct and cultural), and serological diagnosis;
6. Facilitate access to histopathological diagnosis in the absence of mycological diagnosis;

7. Provide stable and reproducible antigens of P. brasiliensis and $P$. lutzii in the public health network;

8. Standardize a serological technique for diagnosis and follow-up at the national level;

9. Stimulate the evaluation of the role of corticosteroids in the treatment of patients with intense and/or extensive inflammatory lesions;

10. Enhance the evaluation of antifungal maintenance therapy in immunosuppressed patients according to the degree of immunodepression;

11. Determine the appropriate moment to introduce antiretroviral therapy to AIDS patients, considering the presence of drug interactions and possibility of IRIS, and establishing the parameters for such evaluations;

12. Create a data bank on the distribution of the different species of Paracoccidoides in the country to be used in epidemiological diagnoses and to launch multicentric projects with serological tests and typing of isolates with the support of consolidated groups and network projects.

\section{AUTHORS' CONTRIBUTION}

General coordination of the consensus: Shikanai-Yasuda MA. Final critical review: Shikanai-Yasuda MA, Martinez R, Moretti ML, Colombo A, Queiroz-Telles F, and Mendes RP. Thematic coordination, design, writing, critical review, and final approval of the version to be published: Shikanai-Yasuda MA, Martinez R, Moretti ML, Colombo A, Queiroz-Telles F, and Mendes RP.

Experts who participated in the composition of the Brazilian Guidelines for the Clinical Management of Paracoccidioidomycosis, 2017 - writing and responsibility for the document in terms of accuracy and integrity: ShikanaiYasuda MA, Martinez R, Moretti ML, Colombo A, QueirozTelles F, Mendes RP, Kono ASG, Paniago AM, Nathan A, Valle ACF, Bagagli E, Benard G, Ferreira MS, Teixeira MM, SilvaVergara ML, Pereira RM, Cavalcante RS, Hahn RC, Durlacher, RR, Khoury Z, and Camargo ZP.

\section{ACKNOWLEDGEMENTS}

We thank the Brazilian Society of Tropical Medicine and Hygiene for supporting this consensus and the translation of this manuscript, the Brazilian Society of Infectology and Sociedade Paulista de Infectologia for supporting this consensus and the Departamento de Moléstias Infecciosas e Parasitárias da FMUSP, for partial support to the coordinators' meeting. We thank the Departamento de Saúde Comunitária, Universidade Federal do Paraná, PR, BR, Disciplina de Infectologia da Universidade Federal de São Paulo, Departamento de CardioPneumologia da FMUSP, Prof. Silvio de Alencar Marques, Faculdade de Medicina de Botucatu, UNESP and Prof. Dr. Carlos P. Taborda, Instituto de Ciências Biomédicas da USP for the photographs. We thank the Editorial Board of the 
Revista da Sociedade Brasileira de Medicina Tropical and the authors and consultants of the "Consenso Brasileiro em Paracoccidioidomicose", 2006, for authorizing the reproduction and modification of the Figures/Tables, the Editorial Board of the Journal of Fungi, for authorizing the reproduction of Figure 3 , the Editorial Board of $m E s p h e r e$, of Figure 1 (modified) and the Editorial Board of Seminary Respiratory Critical Care Medicine, of Table 2 (modified); Alex Adriano da Silva and Vera Lúcia T. Freitas for the technical support in the preparation of the Figures. 3 and 1A, respectively.

\section{DECLARATION OF POTENTIAL CONFLICT OF INTEREST}

This statement was taken to consider only the drugs mentioned in this consensus and whose patents have not been lost in the last five years:

Arnaldo Lopes Colombo, Continuing Medical Education: Gilead, MSD, Pfizer, United Medical and Research Grants from Astellas and Pfizer; Flávio Queiroz Telles, Continuing Medical Education: Gilead, MSD, Pfizer, TEVA, United Medical; Maria Aparecida Shikanai Yasuda, Continuing Medical Education: United Medical.

Other co-authors declare no conflicts of interest.

\section{REFERENCES}

1. Teixeira MM, Theodoro RC, Oliveira FF, Machado GC, Hahn RC, Bagagli E, et al. Paracoccidioides lutzii sp. nov.: biological and clinical implications. Med Mycol. 2014;52(1):19-28.

2. Matute DR, McEwen JG, Puccia R, Montes BA, San-Blas G, Bagagli E, et al. Cryptic speciation and recombination in the fungus Paracoccidioides brasiliensis as revealed by gene genealogies. Mol Biol Evol. 2006;23(1):65-73.

3. Muñoz JF, Farrer RA, Desjardins CA, Gallo JE, Sykes S, Sakthikumar S, et al. Genome diversity, recombination, and virulence across the major lineages of Paracoccidioides. mSphere. 2016;1(5):e00213-16.

4. de Macedo PM, Almeida-Paes R, de Medeiros Muniz M, Oliveira MM, Zancope-Oliveira RM, Costa RL, et al. Paracoccidioides brasiliensis PS2: first autochthonous paracoccidioidomycosis case report in Rio de Janeiro, Brazil, and literature review. Mycopathologia. 2016;181(9-10):701-8.

5. Marques-da-Silva SH, Rodrigues AM, de Hoog GS, SilveiraGomes F, Camargo ZP. Occurrence of Paracoccidioides lutzii in the Amazon region: description of two cases. Am J Trop Med Hyg. 2012;87(4):710-4

6. Teixeira MM, Theodoro RC, Nino-Vega G, Bagagli E, Felipe MS. Paracoccidioides species complex: ecology, phylogeny, sexual reproduction, and virulence. PLoS Pathog. 2014;10(10):e1004397.

7. Theodoro RC, Teixeira MM, Felipe MSS, Paduan KS, Ribolla PM, San-Blas G, et al. Genus Paracoccidioides: species recognition and biogeographic aspects. PLoS One. 2012;7(5):e37694.

8. Hahn RC, Rodrigues AM, Fontes CJF, Nery AF, Tadano T, QueirozJúnior LP, et al. Fatal fungemia due to Paracoccidioides lutzii. Am J Trop Med Hyg. 2014;91(2):394-8.
9. Queiroz-Júnior LP, Camargo ZP, Tadano T, Rodrigues AM, Takarara DT, Gegembauer G, et al. Serological and antigenic profiles of clinical isolates of Paracoccidioides spp. from Central Western Brazil. Mycoses. 2014;57(8):466-72.

10. Wanke B, Londero AT. Epidemiology and paracoccidioidomycosis infection. In: Franco MF, Lacaz CS, Restrepo-Moreno A, Del Negro G, editors. Paracoccidioidomycosis. Boca Raton: CRC Press; 1994. p. 109-20.

11. Lacaz CS, Porto E, Martins JEC, Heins-Vaccari EM, Melo NT. Paracoccidioidomicose. In: Lacaz CS, Porto E, Martins JEC, Heins-Vaccari EM, Melo NT, editors. Tratado de Micologia Médica Lacaz. São Paulo: Sarvier Editora de Livros Médicos Ltda; 2002. p. 639-729.

12. Restrepo-Moreno A. Ecology of Paracoccidioides brasiliensis. In: Franco MF, Lacaz CS, Restrepo-Moreno A, Del Negro G (ed) Paracoccidioidomycosis. 1st ed. Boca Raton: CRC Press; 1994. p. 121-30.

13. Arantes TD, Theodoro RC, Teixeira MM, Bosco SM, Bagagli E. Environmental mapping of Paracoccidioides spp. in Brazil reveals new clues into genetic diversity, biogeography and wild host association. PLoS Neg1 Trop Dis. 2016;10(4):e0004606.

14. Vieira GD, Alves TC, Lima SMD, Camargo LMA, Sousa CM. Paracoccidioidomycosis in a western Brazilian Amazon State: Clinical-epidemiologic profile and spatial distribution of the disease. Rev Soc Bras Med Trop. 2014;47(1):63-8.

15. Barrozo LV, Benard G, Silva ME, Bagagli E, Marques SA, Mendes RP. First description of a cluster of acute/subacute paracoccidioidomycosis cases and its association with a climatic anomaly. PLoS Negl Trop Dis. 2010;4(3):e643.

16. dos Santos WA, da Silva BM, Passos ED, Zandonade E, Falqueto A. Associação entre tabagismo e paracoccidioidomicose: um estudo de caso-controle no Estado do Espírito Santo, Brasil. Cad Saúde Pública. 2003;19(1):245-53.

17. Morejón KM, Machado AA, Martinez R. Paracoccidioidomycosis in patients infected with and not infected with human immunodeficiency vírus: a case control study. Am J Trop Med Hyg. 2009;80(1):359-66.

18. Radisic MV, Linares L, Afeltra J, Pujato N, Vitale RG, Bravo M, et al. Acute pulmonary involvement by paracoccidioidomycosis disease immediately after kidney transplantation: case report and literature review. Transpl Infect Dis. 2017; 19(2):e12655.

19. Shikanai-Yasuda MA, Conceição YM, Kono A, Rivitti E, Campos AF, Campos SV. Neoplasia and paracoccidioidomycosis. Mycopathologia. 2008;165(4-5):303-12.

20. Woyciechowsky TG, Dalcin DC, dos Santos JW, Michel GT. Paracoccidioidomycosis induced by immunosuppressive drugs in a patient with rheumatoid arthritis and bone sarcoma: case report and review of literature. Mycopathologia. 2011;172(1):77-81.

21. Martinez R. New tends in paracoccidioidomycosis epidemiology. J. Fungi. 2017;3(1):1.

22. Coutinho ZF, Silva D, Lazéra M, Petri V, Oliveira RM, Sabroza PC, et al. Paracoccidioidomycosis mortality in Brazil (1980-1995). Cad Saúde Pública. 2002;18(5):1441-54.

23. Coutinho ZF, Wanke B, Travassos C, Oliveira RM, Xavier DR, Coimbra Jr CE. Hospital morbidity due to paracoccidioidomycosis in Brazil (1998-2006). Trop Med Int Health. 2015;20(5):673-80.

24. Benard G. An overview of the immunopathology of human paracoccidioidomycosis. Mycopathologia. 2008;165(4-5):209-21.

25. Benard G, Romano CC, Cacere CR, Juvenale M, MendesGiannini MJ, Duarte AJ. Imbalance of IL-2, IFN-gamma and 
IL-10 secretion in the immunosuppression associated with human paracoccidioidomycosis. Cytokine. 2001;13(4):248-52.

26. Oliveira SJ, Mamoni RL, Musatti CC, Papaiordanou PM, Blotta MH. Cytokines and lymphocyte proliferation in juvenile and adult forms of paracoccidioidomycosis: comparison with infected and non-infected controls. Microbes Infect. 2002;4(2):139-44.

27. de Castro LF, Ferreira MC, da Silva RM, Blotta MH, Longhi LN, Mamoni RL. Characterization of the immune response in human paracoccidioidomycosis. J Infect. 2013;67(5):470-85.

28. Cavassani KA, Campanelli AP, Moreira AP, Vancim JO, Vitali LH, Mamede RC, et al. Systemic and local characterization of regulatory $\mathrm{T}$ cells in a chronic fungal infection in humans. J Immunol. 2006;177(9):5811-8.

29. Ferreira MC, de Oliveira RT, da Silva RM, Blotta MH, Mamoni $\mathrm{RL}$. Involvement of regulatory $\mathrm{T}$ cells in the immunosuppression characteristic of patients with paracoccidioidomycosis. Infect Immun. 2010;78(10):4392-401.

30. Carvalho FMC, Busser FD, Freitas VLT, Furucho CR, Sadahiro A, Kono ASG, et al. Polymorphisms on IFNG, IL12B and IL12RB1 genes and paracoccidioidomycosis in the Brazilian population. Infect Genet Evol. 2016;43:245-51.

31. Romano CC, Mendes-Giannini MJ, Duarte AJ, Benard G. IL-12 and neutralization of endogenous IL-10 revert the in vitro antigenspecific cellular immunosuppression of paracoccidioidomycosis patients. Cytokine. 2002;18(3):149-57.

32. Romano CC, Mendes-Giannini MJS, Duarte AJ, Benard G. The role of interleukin-10 in the differential expression of interleukin$12 \mathrm{p} 70$ and its beta2 receptor on patients with active or treated paracoccidioidomycosis and healthy infected subjects. Clin Immunol. 2005;114(1):86-94.

33. Bellissimo-Rodrigues F, Bollela VR, Da Fonseca BA, Martinez R. Endemic paracoccidioidomycosis: relationship between clinical presentation and patients' demographic features. Med Mycol. 2013;51(3):313-8.

34. Franco M, Mendes RP, Moscardi-Bacchi M, Rezkallah-Iwasso M, Montenegro MR. Paracoccidioidomycosis. Baillière's Clin Trop Med Communic Dis. 1989;4:185-220.

35. Franco M, Montenegro MR, Mendes RP, Marques SA, Dillon NL, Mota NGS. Paracoccidioidomycosis: a recently proposed classification of its clinical forms. Rev Soc Bras Med Trop. 1987;20(2):129-32.

36. Montenegro MR, Franco M. Pathology. In: Franco M, Lacaz CS, Restrepo-Moreno A, Del Negro G, editors. Paracoccidioidomycosis. Boca Raton: CRC Press; 1994. p. 131-50.

37. Fabris LR, Andrade UV, Dos Santos AF, Marques APC, de Oliveira SMVL, Mendes RP, et al. Decreasing prevalence of the acute/ subacute clinical form of paracoccidioidomycosis in Mato Grosso do Sul State, Brazil. Rev Inst Med Trop Sao Paulo. 2014;56(2):121-5.

38. Barbosa W, Daher R, Oliveira AR. Forma linfático-abdominal da blastomicose sul-americana. Rev Inst Med Trop São Paulo. 1968;10(1):16-27.

39. Shikanai-Yasuda MA, Telles Filho FQ, Mendes RP, Colombo AL, Moretti ML e Grupo de Consultores do Consenso em Paracoccidioidomicose. Consenso em paracoccidioidomicose. Rev Soc Bras Med Trop. 2006;39(3):297-310.

40. Ferreira MS. Paracoccidioidomycosis. Pediatr Respir Rev. 2009;10(4):161-5.

41. Mendes RP. The gamut of clinical manifestations. In: Franco M, Lacaz CS, Restrepo-Moreno A, Del Negro G, editors. Paracoccidioidomycosis. Boca Raton: CRC Press; 1994. p. 233-58.
42. Costa AN, Benard G, Albuquerque ALP, Fujita CL, Magri ASK, Salge JM, et al. The lung in paracoccidioidomycosis: new insights into old problems. Clinics. 2013;68(4):441-8.

43. Benard G, Duarte AJ. Paracoccidioidomycosis: a model for evaluation of the effects of human immunodeficiency vírus infection on the natural history of endemic tropical diseases. Clin Infect Dis. 2000;31(4):1032-9.

44. Tobón AM, Agudelo CA, Osorio ML, Alvarez DL, Arango M, Cano LE, et al. Residual pulmonary abnormalities in adult patients with chronic paracoccidioidomycosis: prolonged follow-up after itraconazole therapy. Clin Infect Dis. 2003;37(7):898-904.

45. Machado Filho J, Miranda JL, Teixeira GA. Das seqüelas da blastomicose sul-americana. Hospital. 1965; 68(6):1347-53.

46. Valle ACF, Aprigliano FF, Moreira JS, Wanke B. Clinical and endoscopic findings in the mucosae of the upper respiratory and digestive tracts in post-treatment follow-up of paracoccidioidomycosis patients. Rev Inst Med Trop São Paulo. 1995;37(5):407-13.

47. Marques SA. Paracoccidioidomycosis: epidemiological, clinical, diagnostic and treatment up-dating. An Bras Dermatol. 2013;88(5):700-11.

48. Wanke B, Valle ACF, Oliveira RMZ, Costa RLB. Paracoccidioidomicose. In: Coura, JR, org. Dinâmica das doenças infecciosas e parasitárias. 2nd ed. Rio de Janeiro: Editora Guanabara Koogan, Grupo Editorial Nacional-GEN; 2013. v. 2. p. 1225-37.

49. Del Negro G, Melo EHL, Rodbard D, Melo MR, Layton J, Wachslicht-Rodbard H. Limited adrenal reserve in paracoccidiodomycosis: cortisol and aldosterone responses to 1-24 ACTH. Clin Endocrinol.1980;13(6):553-9.

50. Colombo AL, Faiçal S, Kater CE. Systematic evaluation of the adrenocortical function in patients with paracoccidioidomycosis. Mycopathol. 1994;127(2):89-93.

51. Pereira WC, Raphael A, Sallum J. Lesões neurológicas da blastomicose sul-americana. Arq Neuro-Psiquiatr. 1965;23(2): 95-112.

52. Almeida SM, Queiroz-Telles F, Teive HA, Ribeiro CE, Werneck LC. Central nervous system paracoccidioidomycosis: clinical features and laboratory findings. J. Infect. 2004;48(2):193-8.

53. Martinez R, Meneguelli UG, Dantas RO, Fiorillo AM. O comprometimento gastrintestinal na blastomicose Sul-Americana (paracoccidiodomicose). I Estudo clínico, radiológico e histopatológico. Rev Ass Méd Brasil. 1979;25(1):31-44.

54. Laudanna AA, Betarello A,van Bellen B. South American blastomycosis as a cause of malabsorption and protein-losing enteropathy. Arq Gastroenterol. 1975;12:195-8.

55. Queiroz-Telles F, Escuissato D. Pulmonary paracoccidioidomycosis. Semin Respir Crit Care Med. 2011;32(6):764-74.

56. Arantes TD, Theodoro RC, Teixeira MM, Bagagli E. Use of fluorescent oligonucleotide probes for differentiation between Paracoccidioides brasiliensis and Paracoccidioides lutzii in yeast and mycelial phase. Mem Inst Oswaldo Cruz. 2017;112(2):140-5.

57. Nobrega de Almeida Jr J, Del Negro GM, Grenfell RC, Vidal MS, Thomaz DY, de Figueiredo DS, et al. Matrix-assisted laser desorption ionization-time of flight mass spectrometry for differentiation of the dimorphic fungal species Paracoccidioides brasiliensis and Paracoccidioides lutzii. J Clin Microbiol. 2015;53(4):1383-6.

58. Del Negro GM, Pereira CN, Andrade HF, Palacios SA, Vidal MMS, Charbel CE, et al. Evaluation of tests for antibody response in the follow-up of patients with acute and chronic forms of paracoccidioidomycosis. J Med Microbiol. 2000;49(1):37-46. 
59. Do Valle AC, Costa RL, Fialho Monteiro PC, Von Helder J, Muniz MM, Zancopé-Oliveira RM. Interpretation and clinical correlation of serological tests in paracoccidioidomycosis. Med Mycol. 2001;39(4):373-7.

60. Moreto TC, Marques MEA, de Oliveira MLSC, Moris DV, de Carvalho LR, Mendes RP. Accuracy of routine diagnostic tests used in paracoccidioidomycosis patients at a university hospital. Trans $\mathrm{R}$ Soc Trop Med Hyg. 2011;105(8):473-8.

61. Camargo ZP, Berzaghi R, Amaral CC, Silva SHM. Simplified method for producing Paracoccidioides brasiliensis exoantigens for use in immunodiffusion tests. Med Mycol. 2003;41(6):539-42.

62. Mendes-Giannini MJS, Bueno JP, Shikanai-Yasuda MA, Stoff AMS, Masuda A, Amato Neto V, et al. Antibody response to the $43 \mathrm{kDa}$ glycoprotein of Paracoccidioides brasiliensis as a marker for the evaluation of patients under treatment. Am J Trop Med Hyg. 1990;43(2):200-6.

63. Batista Jr J, de Camargo ZP, Fernandes GF, Vicentini AP, Fontes CJF, Hahn RC. Is the geographical origin of a Paracoccidioides brasiliensis isolate important for antigen production for regional diagnosis of paracoccidioidomycosis? Mycoses. 2010;53(2):176-80.

64. Gegembauer G, Araujo LM, Pereira EF, Rodrigues AM, Paniago AMM, Hahn RC, et al. Serology of paracoccidioidomycosis due to Paracoccidioides lutzii. PLoS Negl Trop Dis. 2014;8(7):e2986.

65. Marques da Silva SH, Colombo AL, Blotta MHSL, Lopes JD, Queiroz-Telles F, Pires de Camargo Z. Detection of circulating gp43 antigen in serum, cerebrospinal fluid and bronchoalveolar lavage fluid of patients with paracoccidioidomycosis. J Clin Microbiol. 2003;41(8):3675-80.

66. Gaviria M, Rivera V, Muñoz-Cadavid C, Cano LE, Naranjo TW. Validation and clinical application of a nested PCR for paracoccidioidomycosis diagnosis in clinical samples from Colombian patients. Braz J Infect Dis. 2015;19(4):376-83.

67. Vidal MS, Del Negro GM, Vicentini AP, Svidzinski TI, MendesGiannini MJ, Almeida AM, et al. Serological diagnosis of paracoccidioidomycosis: high rate of inter-laboratorial variability among medical mycology reference centers. PLoS Negl Trop Dis. 2014;8(9):e3174.

68. Quagliato Júnior R, Grangeia TAG, Massucio RAC, De Capitani EM, Rezende SM, Balthazar AB. Association between paracoccidioidomycosis and tuberculosis: reality and misdiagnosis. J Bras Pneumol. 2007;33(3):295-300.

69. Rodrigues GS, Severo CB, Oliveira FM, Moreira JS, Prolla JC, Severo LC. Association between paracoccidioimycois and cancer. J Bras Pneumol. 2010;36(3):356-62.

70. Ruiz e Rezende LS, Yasuda AG, Mendes RP, Marques AS, NiéroMelo L, Defaveri J, et al. Paracoccidioidomycosis in patientes with lymphoma and review of published literature. Mycopathologia. 2015;179(3-4):285-91.

71. Zavascki AP, Bienardt JC, Severo LC. Paracoccidioidomycosis in organ transplant recipient: case report. Rev Inst Trop Sao Paulo. 2004;46(5):279-81.

72. Goes HFO, Durães SMB, Lima CS, Souza MB, Vilar EAG, Dalston MO. Case Report. Paracoccidioidomycosis in a renal transplant recipient. Rev Inst Med Trop São Paulo. 2016;58:12.

73. Shikanai-Yasuda MA, Duarte MI, Nunes DF, Lacaz CS, Sabbaga E, Abdala E, et al. Paracoccidioidomycosis in a renal transplant recipient. J Med Vet Mycol. 1995;33(6):411-4.

74. Pontes AM, Borborema J, Correia CR, de Almeida WL, Maciel RF. A rare paracoccidioidomycosis diagnosis in a kidney transplant receptor: case report. Transpl Proc. 2015;47(4):1048-50.
75. Radisic MV, Linares L, Afeltra J, Pujato N, Vitale RG, Bravo M, et al. Acute pulmonary involvement by paracoccidioidomycosis disease immediately after kidney transplantation: case report and literature review. Transpl Infect Dis. 2017;19(2):e-12655.

76. Almeida FA, Neves FF, Mora DJ, Reis TA, Sotini DM, Ribeiro BM, et al. Paracoccidioidomycosis in Brazilian patients with and without human immunodeficiency vírus infection. Am J Trop Med Hyg. 2016;96(2):368-72.

77. Weber SAT, Brasolotto A, Rodrigues L, Marcondes-Machado J, Padovani CR, Carvalho LR, et al. Dysphonia and laryngeal sequelae in paracoccidioidomycosis patients: a morphological and phoniatric study. Med Mycol. 2006;44(3):219-25.

78. Boccalandro I, Albuquerque FJM. Icterícia e comprometimento hepático na blastomicose sul-americana. A propósito de 10 casos. Revisão da literatura. Rev Paul Med. 1960;56:350-66.

79. Troncon LEA, Martinez R, Meneghelli UG, Oliveira RB, Iazigi N. Perda intestinal de proteínas na paracoccidioidomicose. Rev Hosp Clín Fac Med São Paulo. 1981;36(4):172-8.

80. Costa AN, Marchiori E, Benard G, Araújo MS, Baldi BG, Kairalla RA, et al. Lung cysts in chronic paracoccidioidomycosis. J Bras Pneumol. 2013;39(3):368-72.

81. Vogelmeier CF, Criner GJ, Martinez FJ, Anzueto A, Barnes PJ, Bourbeau J, et al. Global Strategy for the Diagnosis, Management, and Prevention of Chronic Obstructive Lung Disease 2017 Report. GOLD Executive Summary. Am J Respir Crit Care Med. 2017;195(5):557-82.

82. Restrepo A, Stevens DA, Gómez I, Leiderman E, Angel R, Fuentes J, et al. Ketoconazole: a new drug for the treatment of paracoccidioidomycosis. Rev Infect Dis. 1980;2(4):633-42.

83. Shikanai-Yasuda MA, Benard G, Higaki Y, Del Negro GM, Hoo S, Vaccari EH, et al. Randomized trial with itraconazole, ketoconazole and sulfadiazine in paracoccidioidomycosis. Med Mycol. 2002;40(4):411-7.

84. Diaz M, Negroni R, Montero-Gei F, Castro LG, Sampaio AS, Borelli D, et al. A Pan-American 5-year study of fluconazole therapy for deep mycoses in the immunocompetent host. Pan-American Study Group. Clin Infect Dis. 1992;14(suppl 1):S68-76.

85. Naranjo MS, Trujillo M, Munera MI, Restrepo P, Gomez I, Restrepo A. Treatment of paracoccidioidomycosis with itraconazole. J Med Vet Mycol. 1990;28(1):67-76.

86. Queiroz-Telles F, Goldani LZ, Schlamm HT, Goodrich JM, EspinelIngroff A. Shikanai-Yassuda MA. An open-label comparative pilot study of oral voriconazole and itraconazole for long-term treatment of paracoccidioidomycosis. Clin Infect Dis. 2007;45(11):1462-9.

87. Thompson 3rd GR, Rendon A, Ribeiro Dos Santos R, QueirozTelles F, Ostrosky-Zeichner L, Azie N, et al. Isavuconazole treatment of cryptococcosis and dimorphic mycoses. Clin Infect Dis. 2016;63(3):356-62.

88. Barbosa W, Vasconcelos WMP. Ação da sulfametoxazol associada a trimetoprim na terapêutica da blastomicose sul-americana. Rev Pat Trop. 1973;2:329-39.

89. Lacaz CS, Sampaio SAP. Tratamento da blastomicose sulamericana com anfotericina B. Resultados preliminares. Rev Paul Med 1958;52:443-50.

90. Campos EP, Sartori JC, Hetch ML, De Franco MF. Clinical and serologic features of 47 patients with paracoccidioidomycosis treated by amphotericin B. Rev Inst Med Trop Sao Paulo. 1984;26(4):212-5.

91. Peçanha PM, de Souza S, Falqueto A, Grão-Veloso TR, Lírio LV, Ferreira Jr CUG, et al. Amphotericin B lipid complex in the treatment of severe paracoccidioidomycosis: a case series. Int $\mathrm{J}$ Antmicrobiol Agents. 2016;48(4):428-30. 
92. Ollague JM, de Zuritta AM, Calero G. Paracoccidioidomycosis (South American blastomycosis) successfully treated with terbinafine: first case report. Br J Dermatol. 2000;143(1):188-91.

93. Borges SR, Silva GM, Chambela MC, Oliveira RV, Costa RL, Wanke B, et al. Itraconazole vs. trimethoprimsulfamethoxazole: a comparative cohort study of 200 patients with paracoccidioidomycosis. Med Mycol. 2014;52(3):303-10.

94. Cavalcante RS, Sylvestre TF, Levorato AD, de Carvalho LR, Mendes RP. Comparison between Itraconazole and cotrimoxazole in the treatment of paracoccidiodomycosis. Plos Negl Trop Dis. 2014;8(4):e2793.

95. Medscape English. Drugs \& Diseases. Drug Interaction Checker. Available in April 5, 2017 from: http://reference.medscape.com/ drug-interactionchecker.

96. Epocrates.Athenahealth Inc USA. Interaction check. Available in April 5, 2017 from:: https://online.epocrates.com/interaction-check.

97. Francesconi F, da Silva MTT, Costa RLB, Francesconi VA, Carregal E, Talhari S, et al. Long-term outcome of neuroparacoccidioidomycosis treatment. Rev Soc Bras Med Trop. 2011;44(1):22-5.

98. Benard G, Campos AF, Netto LC, Gonçalves LG, Machado LR, Mimicos EV, et al. Treatment of severe forms of paracoccidioidomycosis: is there a role for corticosteroids? Med Mycol. 2012;50(6):641-8.

99. Blotta MHSL, Altemani AM, Amaral E, Silva LJ, Camargo ZP. Placental involvement in paracoccidioidomycosis. J Med Vet Mycol. 1993;31(3):249-57.

100.Kulay Jr L, Lapa AJ. Drogas na gravidez: manual de orientação. São Paulo: Ponto; 2003. 180p.

101.Levin ASS, Dias MBGS, Oliveira, MS, Lobo RD, Garcia CP e Grupo de colaboradores. Guia de utilização de anti-infecciosos e recomendações para a prevenção de infecções hospitalares. $5^{\mathrm{a}}$ ed. São Paulo: Hospital das Clínicas; 2014. 192p.

102. Tavares W. Antibióticos e quimioterápicos para o clínico. $3^{\mathrm{a}}$ ed. São Paulo: Editora Atheneu, 2014. p. 658. ISBN-13 9788538805205

103.Barraviera B, Pereira PCM, Mendes RP, Machado JM, Lima CRG, Meira DA. Evaluation of acetylator phenotype, renal function and serum sulfadiazine levels in patients with paracoccidioidomycosis treated with cotrimazine (a combination of sulfadiazine and trimethoprim). Mycopathologia. 1989;108(2):107-12.
104.Braga GM, Hessel G, Pereira RM, Escanhoela CAF. Hepatic involvement in pediatric patients with paracoccidioidomycosis: a histological study. Histopathology. 2014;64(2):256-62.

105. Talwalkar JA, Soetikno RE, Carr-Locke DL, Berg CL. Severe cholestasis related to itraconazole for the treatment of onychomycosis. Am J Gastroenterol. 1999;94(12):3632-3.

106.Pereira RM, Bucaretchi F, Barison EM, Hessel G, Tresoldi AT. Paracoccidioidomycosis in children: clinical presentation, follow-up and outcome. Rev Inst Med Trop São Paulo. 2004;46(3):127-31.

107.Shikanai-Yasuda MA. Pharmacological management of paracoccidioidomycosis. Exp Opin Pharmacother. 2005;6(3):38597.

108.Gryschek RCB, Pereira RM, Kono A, Patzina RA, Tresoldi AT, Shikanai-Yasuda MA, et al. Paradoxical reaction to treatment in 2 patients with severe acute paracoccidioidomycosis: a previously unreported complication and its management with corticosteroids. Clin Infect Dis. 2010;50(10):e56-8.

109.Taborda CP, Urán ME, Nosanchuk JD, Travassos LR. Paracoccidioidomycosis: challenges in the development of a vaccine against an endemic mycosis in the Americas. Rev Inst Med Trop São Paulo. 2015;57(suppl 19):21-4.

110. Severo LC, Londero AT, Geyer GR, Porto NS. Acute pulmonary paracoccidioidomycosis in an immunosuppressed patient. Mycopathologia. 1979;68(3):171-4.

111. Batista MV, Sato PK, Pierrotti LC, de Paula FJ, Ferreira GF, Ribeiro-David DS, et al. Recipient of kidney from donor with asymptomatic infection by Paracoccidioides brasiliensis. Med Mycol. 2012;50(2):187-92.

112.Hahn RC, Morato Conceicão YT, Santos NL, Ferreira JF, Hamdan JS. Disseminated paracoccidioidomycosis: correlation between clinical and in vitro resistance to ketoconazole and trimethoprim sulphamethoxazole. Mycoses. 2003;46(8):342-7.

113.Zambuzzi-Carvalho PF, Fernandes AG, Valadares MC, Tavares PM, Nosanchuk JD, Soares CM, et al. Transcriptional profile of the human pathogenic fungus Paracoccidioides lutzii in response to sulfamethoxazole. Med Mycol. 2015;53(5):477-92.

114. Shikanai Yasuda MA, Felipe MS, Bagagli E, Puccia R. Working Group on Paracoccidioidomycosis [internet] updated 2017. Available from: http://www.isham.org/WorkingGroups/ Paracoccidioidomycosis/

\section{Erratum}

\section{Revista da Sociedade Brasileira de Medicina Tropical/Journal of the Brazilian Society of Tropical Medicine Ahead of Print, 2017 - doi: 10.1590/0037-8682-0230-2017}

Ana Maria Paniago

Should read:

Anamaria M. M Paniago

[6]. Departamento de Clínica Médica, Centro de Ciências Biológicas e da Saúde, Universidade Federal de Mato Grosso, Cuiabá, MT, Brasil.

Should read:

[6]. Faculdade de Medicina, Universidade Federal de Mato Grosso do Sul, Campo Grande, MS, Brasil. 